\title{
Impact of Altered Gut Microbiota and Its Metabolites in Cystic Fibrosis
}

\author{
Aravind Thavamani ${ }^{1,+}+\mathbb{D}$, Iman Salem ${ }^{2,+}$, Thomas J. Sferra ${ }^{1}$ and Senthilkumar Sankararaman ${ }^{1, *(D)}$ \\ 1 Department of Pediatrics, Division of Pediatric Gastroenterology, UH Rainbow Babies \& Children's Hospital, \\ Case Western Reserve University School of Medicine, Cleveland, OH 44106, USA; \\ Aravind.Thavamani@UHhospitals.org (A.T.); Thomas.Sferra@UHhospitals.org (T.J.S.) \\ 2 Center for Medial Mycology, Case Western Reserve University School of Medicine, UH Cleveland Medical Center, \\ Cleveland, OH 44106, USA; ims31@case.edu \\ * Correspondence: Senthilkumar.Sankararaman@UHhospitals.org; Tel.: +1-216-844-1765 \\ + Both authors contributed equally and are considered as co-first authors.
}

Citation: Thavamani, A.; Salem, I.; Sferra, T.J.; Sankararaman, S. Impact of Altered Gut Microbiota and Its Metabolites in Cystic Fibrosis. Metabolites 2021, 11, 123. https:// doi.org/10.3390/metabo11020123

Academic Editors: Lluis Arola,

Manuel Suárez Recio and

Cristina Torres-Fuentes

Received: 15 January 2021

Accepted: 20 February 2021

Published: 22 February 2021

Publisher's Note: MDPI stays neutral with regard to jurisdictional claims in published maps and institutional affiliations.

Copyright: (c) 2021 by the authors. Licensee MDPI, Basel, Switzerland. This article is an open access article distributed under the terms and conditions of the Creative Commons Attribution (CC BY) license (https:// creativecommons.org/licenses/by/ $4.0 /)$.

\begin{abstract}
Cystic fibrosis (CF) is the most common lethal, multisystemic genetic disorder in Caucasians. Mutations in the gene encoding the cystic fibrosis transmembrane regulator (CFTR) protein are responsible for impairment of epithelial anionic transport, leading to impaired fluid regulation and $\mathrm{pH}$ imbalance across multiple organs. Gastrointestinal (GI) manifestations in CF may begin in utero and continue throughout the life, resulting in a chronic state of an altered intestinal milieu. Inherent dysfunction of CFTR leads to dysbiosis of the gut. This state of dysbiosis is further perpetuated by acquired factors such as use of antibiotics for recurrent pulmonary exacerbations. Since the gastrointestinal microbiome and their metabolites play a vital role in nutrition, metabolic, inflammatory, and immune functions, the gut dysbiosis will in turn impact various manifestations of $\mathrm{CF}$ - both GI and extra-GI. This review focuses on the consequences of gut dysbiosis and its metabolic implications on CF disease and possible ways to restore homeostasis.
\end{abstract}

Keywords: gut microbiota; microbiome; diversity; cystic fibrosis; dysbiosis; probiotics; metabolites

\section{Introduction}

Cystic fibrosis (CF) is the most common autosomal recessive disease among Caucasians, affecting more than 30,000 patients in the United States and almost 2.5 times this number worldwide [1]. It is characterized by mutations in the gene coding for the cystic fibrosis transmembrane regulator (CFTR) protein. CFTR dysfunction results in impairment of epithelial ion transport $\left(\mathrm{Cl}^{-}\right.$and $\left.\mathrm{HCO}_{3}{ }^{-}\right)$and impaired mucus hydration [2]. Patients with CF have multisystemic involvement characterized by frequent pulmonary exacerbations and various extrapulmonary manifestations involving the gastrointestinal (GI) tract, pancreas, liver, reproductive organs, and skin [3,4]. Recurrent pulmonary infections are the major cause of morbidity and mortality in CF, and often require frequent hospitalizations for management with prolonged courses of antibiotics. Progressive pulmonary involvement can also result in nutritional deficiency related to a decrease in appetite and increased caloric needs from inflammatory catabolism. GI symptoms of CF are often secondary to mucous inspissation and intestinal dysmotility that may manifest as meconium ileus in the newborn period and present with gastroesophageal reflux disease, small intestinal bacterial overgrowth, distal intestinal obstruction syndrome, and constipation later in life.

Microorganisms reside in all mucosal surfaces of the host. The microbiome refers to the collective genes harbored by these microorganisms. As the gut harbors the highest number and most diverse microbiota, gut dysbiosis and its implications have been increasingly recognized in many conditions [5-8]. Microbial diversity is strongly correlated with healthy status and diversity takes both richness (number of microbial species identified in an ecosystem) and evenness (relative abundance of each represented species) into 
consideration $[7,8]$. Reduced gut microbial diversity is observed in several inflammatory, metabolic, immune-related, and systemic diseases [8-10]. Non-homeostatic imbalance in the composition, diversity, or function of these resident microorganisms is termed dysbiosis [7,11-15].

Host-microbe interactions impact various host entities such as immune function, metabolic pathways, growth, and development, yet many of the mechanisms involved in these interactions remain elusive [8,16]. The abnormal GI milieu prevailing in $\mathrm{CF}$ is associated with dysbiosis. Despite increasing recent interest in microbial research in $\mathrm{CF}$, the temporal changes and clinical significance of gut dysbiosis and its effects on the disease process remain poorly understood [6]. About $80 \%$ of gut microorganisms cannot be cultured by standard culture methods $[14,17]$. Technologic advancements now permit accurate profiling of an individual's microbiome composition. The advent of culture-independent molecular methods such as high-throughput next-generation sequencing of the 16 small ribosomal subunit RNA (16S rRNA) deepened our understanding of the gut microbiome, and more sophisticated techniques such as metagenomics, metatranscriptomics, proteomics, and metabolomics, collectively referred to as multiomics, have helped us to understand both taxonomic and functional aspects of dysbiosis in detail $[4,5,7,11,14]$. The application of metagenomics to the culture methods, referred to as culturomics, has extended our insights in further recognizing the relevant microbiota [11]. This review focuses on the implications of gut dysbiosis in CF (Figure 1) and possible ways to restore homeostasis.

\section{Gut Dysbiosis in Cystic Fibrosis}

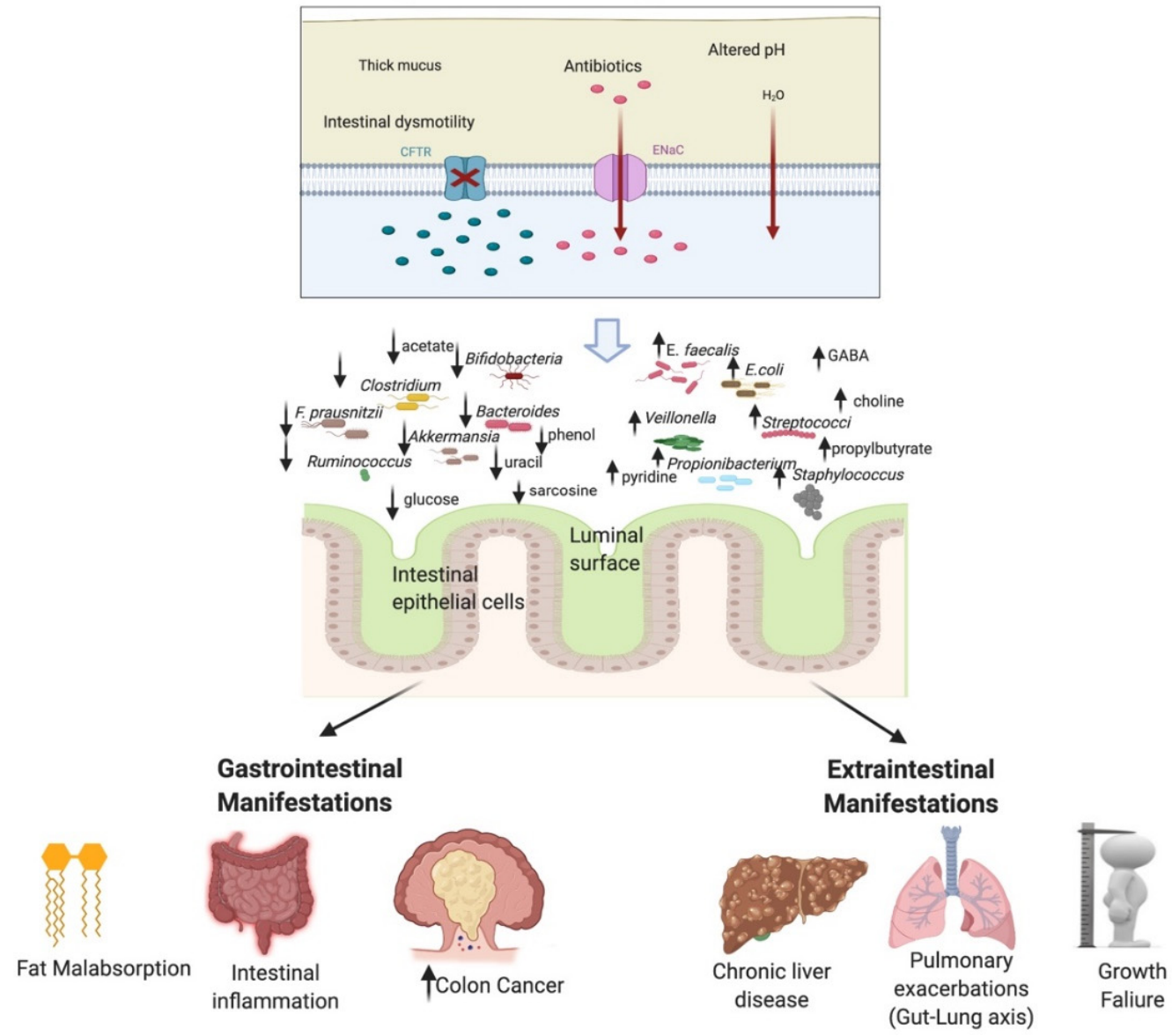

Figure 1. Patterns of gut dysbiosis in cystic fibrosis and their impact on the disease manifestations (created with BioRender.com). $(\downarrow$-decrease; $\uparrow$-increase; F. prausnitzii = Faecalibacterium prausnitzii; E. faecalis = Enterococcus faecalis; E. coli $=$ Escherichia coli GABA = gamma aminobutyric acid) 


\section{Normal Gastrointestinal Microbiota}

\subsection{Normal Gut Microbiota Composition}

Microorganisms inhabiting the gut include bacteria, archaea, viruses, and fungi $[7,8]$. Bacteria are the most studied gut microbes, and the term microbiota is often used synonymously to refer to bacteria $[5,11]$. The microbiome contains approximately five million genes and is two-order times higher than the 23,000 genes in the human genome $[8,10]$. Normal infants have a unique microbial composition; however, by 2-3 years of life, the microbiota more closely resembles that of the adult gut, remaining relatively stable without further perturbations [7,18]. Among the bacterial phyla, Firmicutes and Bacteroidetes predominate in healthy adults and constitute about $90-95 \%$, followed by Proteobacteria and Actinobacteria $[7,8,13,17]$. Other less-frequently represented phyla include Fusobacteria, Verrucomicrobia, and Spirochaetes $[7,13]$. The concentration of commensal bacterial microbiota increases along the GI tract, reaching a maximum of approximately $10^{12}$ cells/gm in the colon $[10,11,13]$. In the GI tract, there also exists a lumen-to-surface gradient, with most species populating the lumen, and some (such as Akkermansia muciniphila and many species of Proteobacteria) are more specialized to reside in the mucosal intestinal layer [10,11]. Most species prevail in the anaerobic environment of the colon.

\subsection{Factors Affecting Gut Microbiota}

The GI microbial milieu is a result of complex dynamic host-microbial interactions of multiple physicochemical factors, such as nutrient availability, anaerobic environment, antimicrobial secretions such as gastric acid and bile, and normal motility of the GI tract [8]. Additionally, the host-specific factors such as genetic composition, dietary changes, exposure to smoking, and medications such as antibiotics further shape the GI microbiota [7,10,11,14,16,19-21]. David et al. reported reproducible substantial and instantaneous alterations in the intestinal microbiome even with short-term diet changes, an observation that was further supported by Carmody et al. in mouse models [22,23]. Elegant work by De Filippo et al. highlighted fecal microbiota in children from Europe and rural Africa as genetically well-adapted, particularly for metabolizing the nutrients in their respective diets [24]. Furthermore, this profound impact of diet can be clearly appreciated when infants are switched from breastfeeding to complementary foods, which helps the maturation of their gut microbiome during the first year of life $[8,25]$. Similarly, antibiotic treatment has a profound and often long-lasting impact on the GI microbial composition, often resulting in a postantibiotic dysbiotic state $[8,25]$.

\subsection{Mutualistic Functions of Gut Microbiota}

Most microbial residents are mutualistic to the host. Microbiome and host interactions are mediated via multiple ways, including the microbial-associated molecular patterns (popularly referred to as the MAMPS) or via several proteins and metabolites expressed by microbial activity, which influence the host via paracrine and endocrine mechanisms $[8,10,14,16]$. In healthy individuals, the gut microbiome plays a vital role in host homeostasis, including prevention of pathogenic infections, supply of essential vitamins, xenobiotic metabolism, energy source via production of short-chain fatty acids (SCFAs), biotransformation of conjugated bile acids, regulation of host metabolism, metabolism of xenobiotics, and elicitation of mucosal immune responses (Table 1 and Figure 2) $[5,7,8,13,16,26,27]$. SCFAs include acetate, butyrate, and propionate, which are produced by anaerobic colonic microbiota as a result of fermentation of indigestible carbohydrates $[16,28,29]$. The prominent SCFA producers include genera Eubacterium, Faecalibacterium, Ruminococcus, and Roseburia, belonging to the order Clostridiales (phylum Firmicutes) and many species of phylum Bacteroidetes [28,29]. SCFAs, importantly butyrate, are crucial for maintaining the intestinal epithelial maturation and homeostasis, colonic sustenance, preservation of epithelial integrity, amelioration of mucosal inflammation, maintenance of colonic $\mathrm{pH}$, and regulation of intestinal motility $[2,9,10,27,29-31]$. 
Table 1. Functions of gut microbiota.

Prevention of pathogenic infections

Synthesis of vitamins (vitamin K and vitamin B complex)

Production of short-chain fatty acids

- Energy source for colonic enterocytes

- Maintenance of epithelial integrity and maturation

- Regulation of intestinal motility

- Amelioration of intestinal inflammation and immune signaling

Regulation of mucosal immune responses

Influence host metabolism and behavior via various endocrine and paracrine functions

Biotransformation of conjugated bile acids

Xenobiotic metabolism

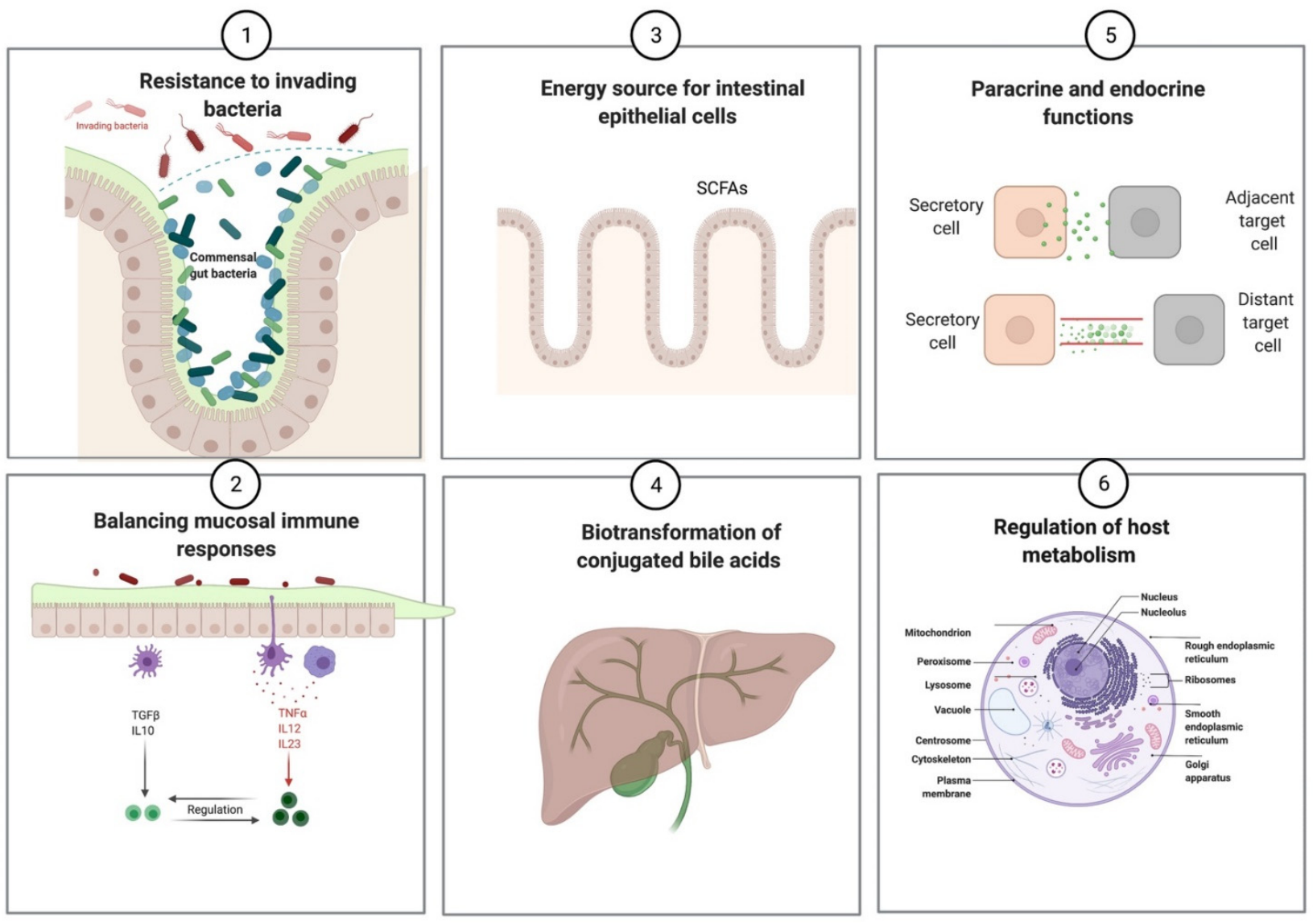

Figure 2. Functions of gut microbiota (Created with https: / / biorender.com/ (accessed on 18 February 2021)). (SCFAs = short-chain fatty acids).

\section{Gut Dysbiosis in Cystic Fibrosis}

\subsection{Mechanisms of Gut Dysbiosis in CF}

The intestinal tract involvement in CF begins during fetal life and is noted in most patients [2,32]. Associated common GI symptoms in CF include abdominal pain, bloating, distention, steatorrhea, poor weight gain, and constipation [2,33]. CFTR is expressed in intestinal epithelial cells, and its dysfunction in CF results in defective CFTR protein, which leads to various physiological and biochemical imbalances. These include thick and inspissated mucus due to chloride channel dysfunction, defective bicarbonate secretion altering the intestinal $\mathrm{pH}$ milieu, prolonged intestinal transit, pancreatic insufficiency, enhanced intestinal inflammation, and altered immune mechanisms with an impaired intestinal barrier function $[9,34-41]$ (Table 2). Clinically, the GI symptoms in CF are mainly related 
to obstruction, malabsorption, and inflammation [2,33]. The changes in the GI ecosystem result in an early and chronic state of gut dysbiosis. Although this dysbiosis is associated primarily with CFTR dysfunction, several acquired factors, such as repeated antibiotic exposures, high-calorie diets, and other medications (acid-suppressive medications, opioids, anticholinergic agents, posttransplant immunosuppressive medications, etc.), may further perpetuate the gut dysbiosis in CF [18,30,40,42,43]. (Figure 1)

Table 2. Mechanisms of gut dysbiosis in cystic fibrosis.

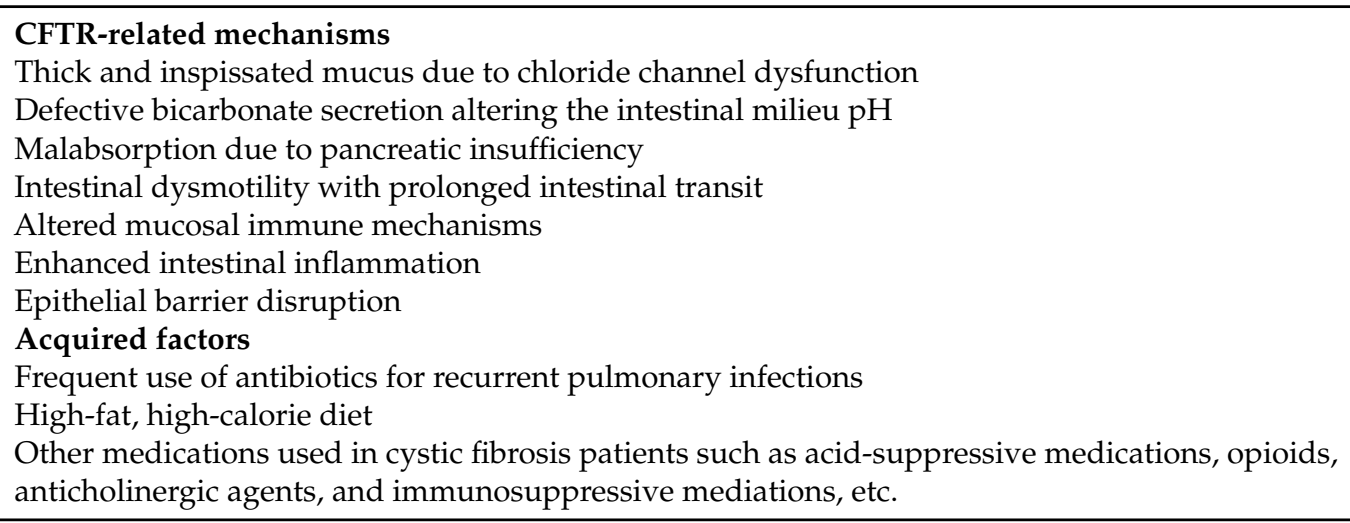

Meeker et al. demonstrated that CFTR dysfunction actively modulates the gut microbiome composition [33]. Using germ-free CF and germ-free non-CF mouse models, fecal microbiota transplantation (FMT) was carried out with fecal inoculum from select pathogen-free mice [33]. Hierarchical analysis based on the relative abundance of the microbiota revealed a distinct microbial pattern due to CFTR dysfunction [33]. Schippa et al. analyzed the effect of different CFTR gene variants and their association with intestinal dysbiosis [44]. A higher degree of gut dysbiosis was observed among patients with severe phenotypic expression and homozygous delF508 mutations, where the predominant groups are Escherichia coli (E. coli) and Eubacterium biforme, with relative depletion of Bifidobacterium and Faecalibacterium species [44]. Microbial representation varied based on whether the patient had one or two alleles with delF508 mutations or other CF-related mutations [44]. A negative correlation was also noted between the utilization of antibiotics and intestinal microbial diversity [45]. In a two-year longitudinal follow-up study, Kristensen and colleagues demonstrated that dysbiosis in CF infants is partly due to antibiotics and antibiotic exposure within the first month of life correlated with reduced alpha diversity (within-sample individual diversity, characterized by the richness and/or evenness of species distribution) [15,37].

In approximately $85 \%$ of CF patients, exocrine pancreatic insufficiency is present, which significantly impacts the absorption of fat and fat-soluble vitamins, necessitating lifelong pancreatic enzyme replacement therapy [46]. The correlation between pancreatic insufficiency and gut dysbiosis is controversial, and further large-scale studies are needed. For example, Nielsen et al. reported that gut dysbiosis was relatively less pronounced in pancreatic-sufficient CF patients compared to patients with pancreatic insufficiency [18]. However, studies by Burke and colleagues did not reveal significant microbial disparities in diversity or abundance in CF patients based on their pancreatic exocrine function [45]. Along with fat malabsorption, the high-calorie, high-fat diet prescribed for CF patients may also predispose them to gut dysbiosis [30]. Mice fed a high-fat diet exhibited gut dysbiosis [47]. Furthermore, Matamouros et al. showed that E. coli fecal isolates from CF patients differed from those without CF, as they showed abundant growth in glycerol medium, which is likely an adaptation due to selective pressure from the increased availability of intestinal fats in CF [48]. 


\subsection{Patterns of Gut Dysbiosis in CF}

\subsubsection{Decrease in Microbial Diversity}

Both pediatric and adult studies demonstrate that the gut microbiota in CF differs taxonomically and functionally from healthy individuals with reduced abundance and species richness, and this distinction begins early in life $[18,42,43,49]$. Many studies are observational in methodology, involving a small number of $\mathrm{CF}$ patients and healthy controls, and of those, only a few are longitudinal (Table 3). Stool samples are utilized in majority of studies, and few evaluated the colonic mucosal microbiome. A consistent finding is decreased microbial diversity in CF patients compared to healthy controls $[18,30,39,45,50,51]$. However, there is controversy as to whether more deviation in the abundance and diversity of operational taxonomic units (OTUs) is observed with progression of age [11,18,52]. As an example, Nielsen et al. illustrated that OTU abundance was significantly lower in CF patients in contrast to control, and that species abundance among 15-year-old CF patients was lower than in a 1-year-old in the control group [18]. Vernocchi et al. described a distinct enterophenotype characteristic of CF patients that was age-independent, and Manor et al. reported that taxonomic and functional microbial changes in young children with $\mathrm{CF}$ decreased with the progression of age [39].

Table 3. Gut microbiome studies in cystic fibrosis.

\begin{tabular}{|c|c|c|c|}
\hline Study Population & Key Findings in CF & Conclusions & References \\
\hline 7 infants with CF enrolled at birth & $\begin{array}{l}\text { High degree of concordance between } \\
\text { gut and respiratory microbial samples. } \\
\text { For seven genera, gut colonization } \\
\text { predicted their appearance in } \\
\text { the lungs }\end{array}$ & $\begin{array}{l}\text { Nutritional factors and gut } \\
\text { colonization patterns could } \\
\text { determine respiratory microbiome } \\
\text { in CF }\end{array}$ & Madan et al., 2012 [20] \\
\hline $\begin{array}{l}21 \text { family units } \\
\text { (one patient with CF and one to } \\
\text { two healthy siblings) }\end{array}$ & $\begin{array}{l}\downarrow \text { Abundance and temporal stability } \\
\text { of Bifidobacteria and Clostridium } \\
\text { cluster XIVa }\end{array}$ & $\begin{array}{l}\text { Dysbiosis in CF could be due to } \\
\text { disease-related impairment of } \\
\text { essential gastrointestinal tract } \\
\text { functions or a side effect of } \\
\text { antibiotic usage }\end{array}$ & Duytschaever et al., 2013 [50] \\
\hline $\begin{array}{l}12 \text { patients with } \mathrm{CF} \text { and } 12 \mathrm{HC} \\
\text { aged several weeks to } 5 \text { years }\end{array}$ & $\begin{array}{l}\uparrow E . \text { coli correlated with nutrient } \\
\text { malabsorption and } \\
\text { intestinal inflammation }\end{array}$ & $\begin{array}{l}\text { E. coli contributed to CF-related } \\
\text { gastrointestinal dysfunction }\end{array}$ & Hoffman et al., 2014 [40] \\
\hline $\begin{array}{l}13 \text { patients with } C F \text { aged } \\
0-34 \text { months }\end{array}$ & $\begin{array}{l}\text { Specific clustering of bacteria in fecal } \\
\text { samples, but not respiratory samples, } \\
\text { were associated with } \\
\text { pulmonary exacerbations }\end{array}$ & $\begin{array}{l}\text { Specific bacterial communities } \\
\text { colonized the gut before the lungs in } \\
\text { CF patients }\end{array}$ & Hoen et al., 2015 [53] \\
\hline $\begin{array}{l}14 \text { patients with } \mathrm{CF} \text { and } 12 \mathrm{HC} \\
\text { aged }<3 \text { years }\end{array}$ & $\begin{array}{l}\uparrow \text { E. coli, E. faecalis, Veillonella, } \\
\text { C. difficile } \\
\downarrow \text { Beneficial Clostridiales } \\
\text { Dysbiosis significantly altered lipid } \\
\text { metabolism ( } \downarrow \text { FFA biosynthesis and } \uparrow \\
\text { anti-inflammatory SCFAs degradation) }\end{array}$ & $\begin{array}{l}\text { Taxonomic and functional microbial } \\
\text { shifts in young children with CF } \\
\text { decreased with age } \\
\text { Gut dysbiosis in CF correlated with } \\
\text { fat malabsorption \& inflammation }\end{array}$ & Manor et al., 2016 [30] \\
\hline $\begin{array}{l}23 \mathrm{HC} \text { and } 35 \text { patients with } \mathrm{CF} \\
\text { (age range } 0-18 \text { years) }\end{array}$ & $\begin{array}{l}\text { Progressive } \downarrow \text { and alteration in } \\
\text { richness and diversity of gut bacteria } \\
\text { that was associated with CF from } \\
\text { early childhood until late adolescence } \\
\text { independent of pancreatic function }\end{array}$ & $\begin{array}{l}\uparrow \text { Deviation in the number and } \\
\text { diversity of intestinal microbiome } \\
\text { with age in CF } \\
\text { Efforts to rectify loss of bacterial } \\
\text { diversity should be conducted no } \\
\text { later than early childhood }\end{array}$ & Nielsen et al., 2016 [18] \\
\hline $\begin{array}{l}43 \text { patients with } \mathrm{CF} \text { aged } \\
21-38 \text { years and } 69 \mathrm{HC} \text { aged } \\
24-40 \text { years }\end{array}$ & $\begin{array}{l}\downarrow \text { Microbial diversity } \\
\uparrow \text { Firmicutes } \\
\downarrow \text { Bacteroidetes }\end{array}$ & $\begin{array}{l}\text { Gut dysbiosis in CF positively } \\
\text { correlated with lung dysfunction and } \\
\text { intravenous antibiotic use }\end{array}$ & Burke et al., 2017 [45] \\
\hline $\begin{array}{l}30 \text { patients with CF ( } 14 \text { were } \\
\text { homozygous for delF508 and } 14 \\
\text { were heterozygous, and } 2 \text { had } \\
\text { mild genotype) age range } \\
10-22 \text { years and } 8 \text { HC (mean age } \\
14.3 \text { years) }\end{array}$ & $\begin{array}{l}\downarrow \text { Clostridium coccoides } \\
\downarrow \text { Bacteroides-Proveotella } \\
\downarrow \text { Bifidobacterium genera } \\
\downarrow \text { Key butyrate producers }\end{array}$ & $\begin{array}{l}\text { Low frequency of sulfate reducing } \\
\text { bacteria in } \mathrm{CF} \\
\text { Significant reduction in } \\
\text { hydrogen-consuming microbes in } \mathrm{CF}\end{array}$ & Miragoli et al., 2017 [54] \\
\hline
\end{tabular}


Table 3. Cont.

\begin{tabular}{|c|c|c|c|}
\hline Study Population & Key Findings in CF & Conclusions & References \\
\hline $\begin{array}{l}31 \text { patients with } C F \text { between } \\
1-6 \text { years and age-matched } 1: 1 \mathrm{HC}\end{array}$ & $\begin{array}{l}\uparrow \text { Propionibacterium, Staphylococcus, } \\
\text { C. difficile } \\
\downarrow \text { Eggerthella, Eubacterium, } \\
\text { Ruminococcus, F. prausnitzii, } \\
\text { Lachnospiraceae } \\
\uparrow \text { GABA, choline, propylbutyrate, and } \\
\text { pyridine } \downarrow \text { Sarcosine, methylphenol, } \\
\text { uracil, glucose, acetate, phenol, } \\
\text { and benzaldehyde }\end{array}$ & $\begin{array}{l}\text { CF gut microbiota revealed an } \\
\text { enterophenotype that was correlated } \\
\text { with disease status regardless of age } \\
\text { and pancreatic status. This distinct } \\
\text { dysbiosis was partially related to } \\
\text { pulmonary infections and oral } \\
\text { antibiotic use }\end{array}$ & Vernocchi et al., 2018 [39] \\
\hline $\begin{array}{l}27 \text { patients with } \mathrm{CF} \text { and } \\
\text { age/gender matched HC (age } \\
\text { range } 0.8-18 \text { years) }\end{array}$ & $\begin{array}{l}\text { Prominent taxonomic and functional } \\
\text { dysbiosis in CF compared to HC } \\
\downarrow \text { richness and diversity of gut } \\
\text { microbiota in CF }\end{array}$ & $\begin{array}{l}\text { Enrichment of genes involved in } \\
\text { SCFAs, antioxidant and nutrient } \\
\text { metabolisms in CF }\end{array}$ & Coffey et al., 2019 [9] \\
\hline $\begin{array}{l}21 \text { patients with CF and } \\
409 \text { healthy infant controls }\end{array}$ & $\begin{array}{l}\text { Unlike the healthy infants, the alpha } \\
\text { diversity did not increase in CF infants } \\
\downarrow \text { Bacteroides } \\
\downarrow \text { Roseburia } \\
\uparrow \text { Veillonella }\end{array}$ & $\begin{array}{l}\text { The distinct CF gut microbiota in } \\
\text { infants was associated with } \\
\text { pulmonary exacerbations. In vitro } \\
\text { models suggested the role of } \\
\text { Bacteroides in reduction of IL- } 8 \\
\text { linking the gut dysbiosis in } \\
\text { CF-related inflammation }\end{array}$ & Antosca et al., 2019 [55] \\
\hline $\begin{array}{l}20 \text { patients with } \mathrm{CF} \text { and } 45 \mathrm{HC} \text {, } \\
\text { fecal samples collected over the } \\
\text { first } 18 \text { months of life }\end{array}$ & $\begin{array}{l}\downarrow \text { Akkermansia, Bifidobacterium, } \\
\text { Bacteroides and Anaerostipes } \\
\uparrow \text { Streptococci, Enterococcus and E. coli } \\
\downarrow \text { Alpha diversity }\end{array}$ & $\begin{array}{l}\text { Antibiotic use in infants with CF was } \\
\text { associated with a lower alpha } \\
\text { diversity and altered microbial } \\
\text { composition }\end{array}$ & Kristensen et al., 2020 [37] \\
\hline 207 infants with CF and $25 \mathrm{HC}$ & $\begin{array}{l}\downarrow \text { Bacteroidetes } \\
\uparrow \text { Proteobacteria }\end{array}$ & $\begin{array}{l}\text { CF infants with low length had } \\
\text { pronounced dysbiosis than } \mathrm{HC} \text { and } \\
\text { CF infants with normal length }\end{array}$ & Hayden et al, 2020 [26] \\
\hline
\end{tabular}

(CF = cystic fibrosis; $\downarrow$-decrease; $\uparrow$-increase; HC = healthy controls; E. coli = Escherichia coli; E. faecalis = Enterococcus faecalis; C. difficile = Clostridiales difficile $;$ FFA $=$ free fatty acids; SCFAs = short-chain fatty acids; F. prausnitzii = Faecalibacterium prausnitzii; GABA = gamma aminobutyric acid; IL-8 = interleukin-8).

\subsubsection{Alteration of Gut Microbial Composition}

Along with reduced gut microbial diversity, there is a significant alteration of microbial composition in patients with CF $[9,26,30,37,39,40,50,55]$ (Table 4 and Figure 1), For example, an increase in Firmicutes, a reduction in Bacteroidetes, along with a higher abundance of pro-inflammatory microbiota such as those belonging to Enterobacteriaceae, Streptococcus, and Veillonella are consistently reported in patients with CF [6,45]. Metagenomic analysis revealed that the hallmark of gut dysbiosis in CF is the significant increase in $\gamma$-Proteobacteria concentration with the predominant order Enterobacterales. Enterobacteriaceae-dominant dysbiosis driven by a higher relative abundance of $E$. coli species has been frequently observed in CF and often noted early in life $[40,56]$. Manor et al. also reported an increase in the species Enterococcus faecalis and Enterococcus faecium, known to frequently exhibit antibiotic resistance [30]. In addition, several studies note that CF patients have relative depletion of genus Bifidobacterium and Clostridium compared to their healthy siblings and controls $[30,40,48,50,57,58]$. Longitudinal follow-up by Duytschaever et al. demonstrated a consistent lower temporal stability and reduced species abundance in CF patients compared to the control population [50]. The CF infants also had a reduced abundance of beneficial strains such as Akkermansia, Eggerthella, Anostipes, and Clostridium IV [37]. Further, there was a significant decrease in Bacteroides - a genus thought to be associated with immune modulation [55,59].

Early and prolonged exposure to antibiotics in patients with $\mathrm{CF}$ further exacerbates the alteration of the microbial composition [2,37]. Prominent butyrate producers such as Anaerostipes, Butyricicoccus, and Ruminococcus are reduced with antibiotic treatment in CF [37]. Also, the abundant Enterobacteriaceae species in CF exhibited resistance to amoxicillin compared to healthy subjects [50]. Antibiotic prescription practices were identified to contribute to this relative abundance of resistant strains among these patients [50]. Further investigations revealed that $E$. coli isolated from $\mathrm{CF}$ and controls revealed a differential 
gene expression. The $\mathrm{CF}$ isolates revealed a growth-promotional transcription profile, as opposed to a stress-associated, stationary-phase profile observed in control isolates [48].

Table 4. Features of gut dysbiosis in cystic fibrosis.

\begin{tabular}{|c|c|c|}
\hline & Increase & Decrease \\
\hline Phylum level & $\begin{array}{l}\text { Firmicutes/Bacteroidetes ratio } \\
\gamma \text {-Proteobacteria }\end{array}$ & $\begin{array}{l}\text { Bacteroidetes } \\
\text { Firmicutes } \\
\text { Actinobacteria }\end{array}$ \\
\hline Genus/Species level & $\begin{array}{c}\text { Pro-inflammatory microbiota } \\
\text { Enterobacteriaceae } \\
\text { Streptococcus } \\
\text { Veillonella } \\
\text { Staphylococcus } \\
\text { Propionibacterium (promoted by low } \\
\text { pH and anaerobic milieu) } \\
\text { Colorectal cancer-related microbiota } \\
\text { Fusobacterium } \\
\text { Veillonella } \\
\text { Escherichia coli (growth-promotional } \\
\text { transcription profile) } \\
\text { Antibiotics-resistant species } \\
\text { Enterococcus faecalis } \\
\text { Enterococcus faecium } \\
\text { Pro-inflammatory species } \\
\text { Veillonella dispar } \\
\text { Clostridiales difficile }\end{array}$ & $\begin{array}{c}\text { Beneficial microbiota } \\
\text { Bifidobacterium } \\
\text { Clostridium } \\
\text { Akkermansia } \\
\text { Eggerthella } \\
\text { Immune modulatory } \\
\text { microbiota } \\
\text { Bacteroides species } \\
\text { Butyrate producers } \\
\text { Anaerostipes } \\
\text { Butyricicoccus } \\
\text { Ruminococcus } \\
\text { Faecalibacterium prausnitzii } \\
\text { Eubacterium rectale } \\
\text { Blautia species } \\
\text { Anti-inflammatory species } \\
\text { Bifidobacterium adolescentis }\end{array}$ \\
\hline Metabolite level & $\begin{array}{c}\text { Gamma aminobutyric acid } \\
\text { Choline } \\
\text { Ethanol } \\
\text { Propylbutyrate } \\
\text { Pyridine }\end{array}$ & $\begin{array}{l}\text { Butyric acid } \\
\text { Pantetheine } \\
\text { Sarcosine } \\
\text { Methylphenol } \\
\text { Uracil } \\
\text { Glucose } \\
\text { Acetate } \\
\text { Phenol } \\
\text { Benzaldehyde } \\
\text { Methylacetate }\end{array}$ \\
\hline
\end{tabular}

\subsection{Gut Dysbiosis with Altered Proteomics and Metabolomics in CF}

Stool proteomic and metabolomic estimation techniques are helpful in further elucidating the functional aspects of dysbiosis [4]. Using 16S rRNA sequencing and metabolomics in stool samples from children with CF, Vernocchi and colleagues demonstrated abundant Propionibacterium, Staphylococcus and Clostridiaceae along with reduced abundance of Eggerthella, Eubacterium, Ruminococcus, Dorea, Faecalibacterium prausnitzii (F. prausnitzii), and Lachnospiraceae, and further noted that the resulting dysbiosis was associated with increased expression of metabolites such as gamma aminobutyric acid (GABA), choline, ethanol, propylbutyrate, and pyridine; and reduced levels of sarcosine, 4-methylphenol, uracil, glucose, acetate, phenol, benzaldehyde, and methylacetate [39] (Figure 1).

Utilizing liquid chromatography-mass spectrometry on stool protein extracts from CF patients and their healthy siblings as controls, Debyser et al. revealed the association of proteins intricately involved in inflammatory and mucus production pathways in CF patients [38]. The detailed microbial analysis revealed a decrease in butyrate reducing bacteria such as F. prausnitzii and an increase in Enterobacteriaceae, Ruminococcus gnavus and Clostridia species [38]. The stool metabolites between CF (in both pancreatic-sufficient and pancreatic-insufficient patients) and healthy controls differed significantly in abundance. A post hoc analysis revealed a decrease in butyric acid and pantetheine (which is needed for conversion of propanoate to propionyl coenzyme A) in CF $[9,60]$. Further, 
the investigators noted a high level of lipoyl-GMP, which could be utilized as a potential stool inflammatory marker [60]. The acidic intestinal milieu prevalent in CF may promote the growth of selective anaerobes such as Clostridiales difficile and Propionibacterium, which are known to produce metabolites such as alcohols, esters, and pyridine [39]. Wang et al. demonstrated that the commensal genus Faecalibacterium was strongly associated with SCFA production in healthy individuals [36]. This genus was substituted by Clostridium sensu stricto 1 in CF patients [36]. In a subset of CF patients, enterococcal overgrowth was noted, which was associated with increased lactate and reduced SCFA biosynthesis [36].

\section{Impact of Gut Dysbiosis on Cystic Fibrosis Manifestations}

\subsection{Impact on the Gastrointestinal Tract}

\subsubsection{Increase Intestinal Inflammation and Barrier Permeability}

Alteration of the gut microbial milieu has been hypothesized as one of the contributors for intestinal inflammation and subsequent barrier impairment in CF [2,9,30,40,57,58,61-64] (Figure 1). Based on taxonomic and inferred functional dysbiosis prediction, children with CF had an increased abundance of pro-inflammatory pathogens such as Staphylococcus, Streptococcus, Escherichia, Shigella, Enterobacter, Morganella, and Veillonella dispar, along with decreased anti-inflammatory microbes like Bacteroides, Bifidobacterium adolescentis, and $F$. prausnitzii $[9,30,33,37,40,48]$. These findings are associated with ongoing intestinal inflammation as shown by the high level of fecal inflammatory markers [65-69]. Interestingly, the dysbiotic changes were similar to those reported in Crohn's disease (CD), indicating a possibility of dysbiosis-mediated increased inflammation with intestinal permeability [59]. Additionally, in CF mice, decreased Lachnoclostridium and Parabacteroides were found to be associated with increased TH17 cells in the spleen, likely as a result of increased intestinal permeability [33]. The increased gut permeability in CF has been observed in both CF mouse models and human studies, and is attributed to many causes, including the CFTR dysfunction [63,70-72]. Essential fatty-acid deficiency, abnormalities in tight junctions, and decreased intestinal alkaline phosphatase are the other factors implied in increased intestinal permeability [63,70-73]. Intestinal alkaline phosphatase is an important mucosal defense factor necessary for gut homeostasis, and the low alkaline phosphatase activity in $\mathrm{CF}$ is secondary to increased release from the intestinal brush border, along with the faulty handling of this enzyme in post-Golgi compartments as a result of accumulation of the incorrectly glycosylated CFTR in these structures $[63,70,74]$. Thus the pattern of gut dysbiosis in CF may perpetuate intestinal inflammation and subsequent barrier impairment.

\subsubsection{Alteration of Fat Metabolism}

Compared to healthy controls, patients with CF exhibited significantly decreased acetogens along with a reduction in butyrate producers such as F. prausnitzii, Eubacterium rectale, Blautia spp., Ruminococcaceae, and Bacteroides, resulting in substantial effects on hostcell metabolism $[6,18,44,50,54,75]$. Manor et al. demonstrated that children with CF had overall reduced potential in fatty-acid biosynthesis and an enhanced capacity for degrading butyrate and propionate compared to the healthy controls [30]. Similarly, Coffey et al., based on predicted functional analysis, reported an upregulation of the genes involved in the metabolism of propanoate and butyrate in CF patients [9,30]. Altered SCFA metabolism is noted in association with intestinal inflammation, and other metabolic effects such as poor bone growth $[6,9,10,30]$. Furthermore, functional dysbiosis is also associated with fat malabsorption, and as a result, the microbiome of CF patients are constantly exposed to high luminal fat content [30]. This may in turn contribute to the microbiome's enhanced ability of fatty-acid metabolism [76]. The increased abundance of E. coli in CF patients was positively correlated with intestinal inflammation and altered lipid metabolism and absorption, thus potentially contributing to poor nutrition status [40]. (Figure 1) 


\subsubsection{Gut Dysbiosis and Colon Cancer in CF}

Colon cancer is about $5-10$ times more prevalent in CF patients, and also occurs 2-3 decades earlier compared to the general population [77,78]. Gut inflammation is thought to play a key role in this predisposition to cancer in CF patients [41,78]. Along with intestinal inflammation, many other factors have been associated with this increased cancer predisposition, including the disruption of Wnt/ $\beta$-catenin signal pathways, disturbances in gut stem-cell homeostasis, epithelial cell-junction disruptions, gut dysbiosis, and immune-cell infiltration [51,77] (Figure 1). Fusobacterium, widely associated with colorectal cancer, is observed to be also abundant in stool and colonic mucosal samples of patients with CF $[9,51,79]$. Dayama et al. demonstrated associations between gut dysbiosis, host-microbiome-gene interactions, and enrichment of oncogenic pathways [51]. Colonic mucosal RNA-seq was determined and 1543 expressed host genes were studied, along with an evaluation of mucosal dysbiosis using $16 \mathrm{~S}$ rRNA sequencing [51]. Here, the authors reported the association of dysbiotic changes, like reduction in the butyrate producers Ruminococcaceae and Butyricimonas, and the increase in Actinobacteria, Clostridium, and the proinflammatory colorectal cancer-related microbiota Veillonella with the high expression of colorectal cancer-related genes such as lipocalin 2 (LCN2) and dual oxidase 2 (DUOX2) [51].

\subsection{Extraintestinal Implications of Gut Dysbiosis in CF}

\subsubsection{Gut Dysbiosis and Liver Involvement in CF}

The role of gut dysbiosis in several liver disorders, such as nonalcoholic fatty liver disease, parenteral nutrition-associated liver disease, and primary sclerosing cholangitis, is increasingly recognized and referred to as a gut-liver axis $[27,31,80]$. Most common manifestations of liver involvement in CF include elevated liver enzymes and hepatic steatosis; the less common yet more severe presentation is termed as CF-related liver disease (CFLD) [80]. The exact pathophysiology of CFLD remains elusive. The conventional hypothesis includes CFTR dysfunction in the biliary epithelial cells, causing thick, tenacious bile leading to focal biliary cirrhosis, which may later progress to multifocal biliary cirrhosis $[3,80]$. Noncirrhotic portal hypertension with obliterative portal venopathy and nodular regenerative hyperplasia has been recently reported in children and young adults with $\mathrm{CF}$, and their pathogenesis remains elusive [81].

Many investigators propose an alternate hypothesis for CFLD lying within the gutliver axis model. Gut dysbiosis in CF may contribute to increased intestinal permeability, encouraging the entry of inflammatory mediators into the portal circulation and leading to activation of hepatic stellate cells [80]. Using video-capsule endoscopy, Flass and colleagues showed that the relative abundance of Bacteroides were reduced in $\mathrm{CF}$ patients with cirrhosis, which was associated with lower intestinal inflammation [82]. Also, they demonstrated that the Clostridium were more abundant in CF patients with cirrhosis, correlating with gut inflammation [82]. Additionally, CF patients with cirrhosis had slower transit, further underpinning the association with intestinal dysmotility, CFLD, and dysbiosis [82]. Debray et al. demonstrated CF-related biliary changes in Cftr - / - mice (both in congenic C57BL/6J and C57BL/6J;129/Ola haplotype backgrounds). These mice were randomly fed either with a medium-chain triglyceride (MCT)-based diet or chow with polyethylene glycol [3]. C57BL/6J Cftr- / - mice fed on an MCT-based diet developed biliary changes similar to CFLD, which correlated with dysbiosis, including E. coli preponderance, low-grade intestinal inflammation, enhanced gut permeability, and lack of secondary bile acids [3]. Cftr- / - mice fed with chow with polyethylene glycol did not develop cholangiopathy and also demonstrated a significant decrease in intestinal inflammation and concomitant decrease in E. coli [3]. The mixed C57BL/6J;129/Ola haplotype group did not develop cholangiopathy when fed with MCT; instead, they developed fatty-liver disease [3]. In CF mouse models, colitis was associated with biliary damage and portal inflammation, which was improved with antibiotics, further pointing to the possible role of gut-derived microbial products in the pathogenesis of CFLD [83] (Figure 1). Furthermore, when incubated with microbiota-derived metabolites like lipopolysaccharides, biliary epithelial cells 
secreted significantly more cytokines, which were mediated mainly by pro-inflammatory pathways like toll-like receptor-4 (TLR4) and NF- $\mathrm{kB}$ [83]. In mice models, the hepatic transcriptome profile in C57BL/6 $\mathrm{Cftr}-/-$ also showed increased expression of genes related to inflammation and reduced expression of genes related to immune tolerance [3]. Utilizing proteomics methodology, serum TIMP-4 and endoglin were noted to be increased in patients with CFLD, demonstrating a potential for a noninvasive biomarker for liver fibrosis [84]. However, this study did not evaluate the gut dysbiosis.

\subsubsection{Effect of Gut Dysbiosis on Growth Failure and Glucose Metabolism in CF Patients}

Loman et al. reported that the relative abundance of Staphylococcus and Faecalibacterium species was negatively correlated with weight-for-length in young children with $\mathrm{CF}$, while there was no significant association noted between alpha diversity with any anthropometric measurements, including body mass index Z scores [19]. Conversely, the beta diversity (between-sample diversity) varied significantly between normally growing and stunted CF populations [15,55]. Additionally, decreased length has been attributed to fecal microbial dysbiosis in infants with CF [26] (Figure 1). They also had decreased abundance of Bacteroidetes and a higher relative abundance of Proteobacteria compared to normal controls [26]. Further, 12/13 SCFA-producing species were significantly less pronounced in CF infants [26]. Dysbiosis has been extensively studied in diabetes, and similarly, CF-related diabetes also could primarily influence the gut dysbiosis, but needs further elucidation $[13,85]$. Investigators reported that the high relative abundance of Alistipes in CF patients was related to impaired glucose homeostasis, given its prominent role in succinate metabolism [9].

\subsubsection{Gut Dysbiosis and Respiratory Microbiome Interactions}

Patients with CF often have progressive obstruction of the airway with tenacious purulent secretions, which alter the respiratory microbiome. Similar to the intestinal microbiome, the microbial composition of the airway is also influenced by factors such as antibiotics and the severity of underlying disease process, which affects the mucosal rheology and leads to differential microbial colonization, and eventually dysbiosis [11]. In healthy cohorts, there is a continuum of the microbial flora from the upper to the lower respiratory tract [86]. However, this continuum is disrupted in CF patients, and a profound difference was noted in the diversity of flora between upper and lower airways, while demonstrating a significant correlation with the disease severity $[87,88]$. Proteobacteria and Actinobacteria are the dominant phyla in the CF lung microbiome [11]. Similar to gut dysbiosis, respiratory dysbiosis also impacts malnutrition, growth failure, and long-term respiratory and other CF comorbidities [89]. In CF, both lung and gut dysbiosis starts very early in life, and both could mutually impact each other $[10,11,53,82]$. Studies have shown a significant crossover between the respiratory microbiome and gut microbiome in CF patients with comparable changes in trend over time, highlighting a complex interplay between these two microbial populations $[6,20,90]$. The gut microbiome has been postulated to influence the airway microbiome via many mechanisms, such as the gut microbial gene products, including proteins and metabolites $[10,11,90]$. Similarly, microbial lung changes could impact the gut microbiome. For example, increased airway exacerbations in pediatric patients were positively correlated with gut dysbiosis [55]. Also, CF patients with severe lung dysfunction had significantly reduced gut microbiota diversity compared to patients with mild or moderate dysfunction [45]. This complex bidirectional influence is referred to as the gut-lung axis.

In a recent study, Antosca et al. demonstrated that intestinal dysbiosis is seen in children as early as six weeks of life, and this is associated with systemic inflammation and immune dysregulation leading to pulmonary exacerbations [55]. Additionally, GI dysbiosis induced by administration of nonabsorbable streptomycin treatment was associated with alterations in the pulmonary inflammatory cell profile, as well as airway hyperresponsiveness [91]. Burke et al. demonstrated a positive correlation between the diversity of the 
intestinal microbiome and the predicted forced expiratory volume in one second (FEV1) value [45]. On the contrary, in a recent study, no significant association was noted between the FEV1 or recent pulmonary exacerbation with the fecal microbiome species [19].

Studies on the lung microbiome have always dominated the landscape, but only few GI microbiome studies have shown association with clinical disease phenotypes and airway microbiome [92]. Hoen et al. and Madan et al. both documented an association between gut and respiratory microbiota in children with CF [20,53]. They found that a gut dysbiotic pattern characterized by pro-inflammatory microbiota like Escherichia, Enterococcus, Parabacteroides and Blautia over immunomodulatory genera like Bacteroides and Bifidobacterium [20,53]. These changes also preceded the pulmonary Pseudomonas aeruginosa colonization in this cohort $[20,53]$. Serial analyses of the gut and respiratory microbial samples in CF infants revealed an overlap between the two microbiota with a core microbiota dominated by Veillonella and Streptococcus [20]. The relative abundance of airway Veillonella is positively correlated with airway inflammation in CF patients $[9,20,53]$. Furthermore, the increased fecal Streptococcus abundance in children with intestinal inflammation appears to be specific to CF and convincingly argues for the hypothesis of the gut-lung axis [59]. The gut inflammation further perpetuates the intestinal-barrier impairment, resulting in the leakage of the pathogenic gut microbiome and their biologically active lipopolysaccharides to the circulation, which may explain the significant overlap with the respiratory microbiome and impact on the airways $[2,64,93]$.

\section{Methods to Modulate the Dysbiosis in Cystic Fibrosis}

Various methods aimed at modulating the gut dysbiosis in CF include specific antibiotic therapy, dietary interventions, and FMT $[9,89]$. FMT is recommended for recurrent severe Clostridioides difficile infections, yet remains experimental for other indications. Potential nutritional strategies for modulating gut dysbiosis include modifications in macronutrient composition; supplementation of micronutrients; administration of probiotics, prebiotics (indigestible carbohydrates), or both (referred as synbiotics); and certain flavonoids [12,49,94]. (Figure 3 and Table 5).

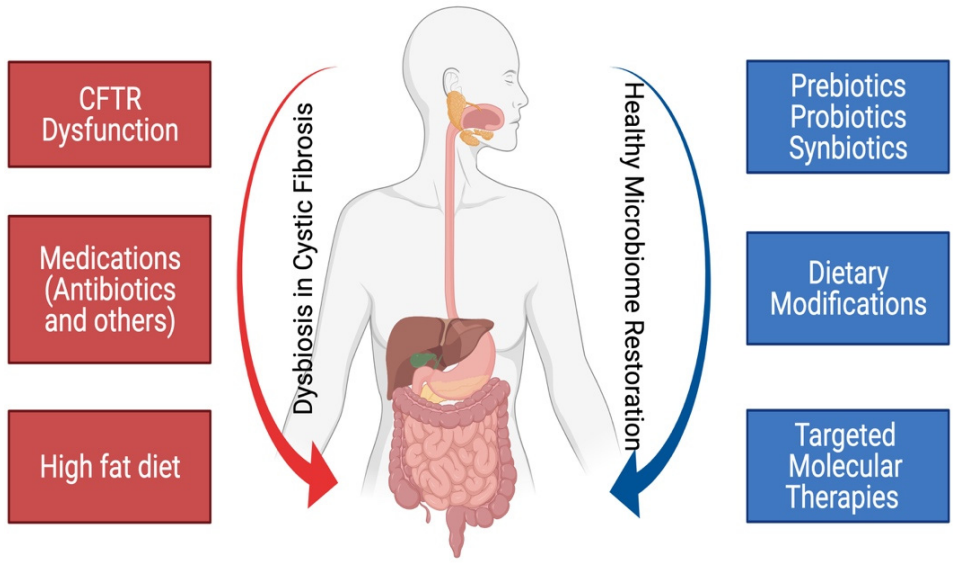

Figure 3. Gut dysbiosis in cystic fibrosis and therapies that aim to modulate the dysbiosis.

Table 5. Therapies that aim to modulate the effect of gut dysbiosis in cystic fibrosis.

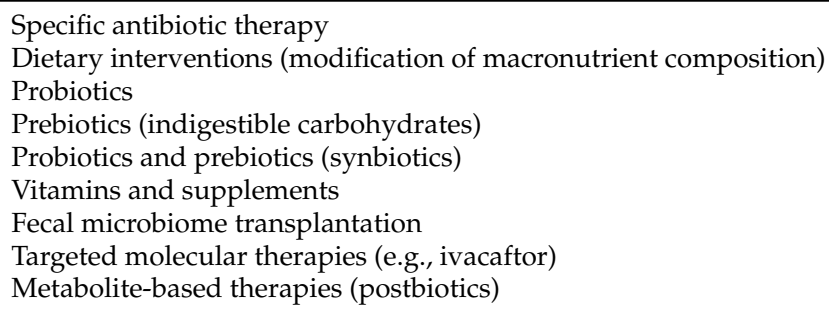




\subsection{Probiotics in Modulation of Gut Microbiome in CF}

In their randomized control trial, Di Nardo et al. showed that supplementation with Lactobacillus reuteri ATCC55730 was associated with significantly decreased pulmonary exacerbations among CF patients with mild to moderate pulmonary involvement with the number needed to treat a value of 3 [95]. In addition to reducing pulmonary exacerbations, other studies have reported a significant decline in hospitalizations and improved quality of life $[96,97]$. The mechanisms of probiotic-mediated reduction of pulmonary exacerbations may include decreasing prevalence of potentially pathogenic microbiota such as Proteobacteria (Enterobacteriaceae), and Fusobacterium species and promotion of beneficial strains, such as Lactobacillus GG and Bifidobacterium species. Lactobacillus GG administration can reduce intestinal inflammation, as proven by decreases in calprotectin levels and increased digestive function after probiotic administration [56]. Similarly, Lactobacillus reuteri supplementation was found to be associated with decreased fecal calprotectin and rectal nitric oxide levels, along with a trend toward restoring eubiosis among CF patients [56,61,98]. Additionally, probiotic intake was also reported to improve intestinal-barrier function [64]. Despite their rare and minimal adverse effects, at present, the routine prescription of probiotics in CF management is not recommended based on limited evidence [43,99]. Probiotic intervention studies in patients with CF are summarized in Table 6.

Table 6. Probiotic intervention studies in cystic fibrosis.

\begin{tabular}{llll}
\hline Study Population & Probiotic Strains & Clinical Responses & Proposed Mechanisms \\
\hline 19 patients & $L G G^{*}$ & $\begin{array}{l}\downarrow \text { Pulmonary exacerbations } \\
\text { and hospital admissions }\end{array}$ & $\begin{array}{l}\downarrow \text { DCs* maturation } \\
\text { resulting in induction } \\
\text { of Treg*-cells }\end{array}$ \\
\hline
\end{tabular}

\begin{tabular}{|c|c|c|}
\hline $\begin{array}{l}37 \text { patients } \\
\text { ( } 20 \text { received probiotics and } \\
17 \text { took placebo capsules) }\end{array}$ & 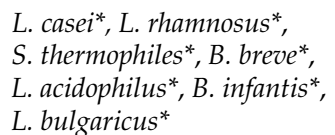 & $\begin{array}{l}\downarrow \text { Pulmonary } \\
\text { exacerbations and } \\
\text { improving quality of life }\end{array}$ \\
\hline
\end{tabular}

\section{Preventing deleterious} effects of inflammatory cytokines (TNF- $\alpha$ * IFN- $\gamma^{*}$ )

Normalization of gut permeability in $13 \%$ of patients. No change in $\mathrm{BMI}^{*}, \mathrm{FEV}^{* \%} \%$, abdominal pain, and pulmonary exacerbations
L. rhamnosus* SP1 (DSM
21690) \& B. animalis

spp.BLC1 (LGM23512)

\section{Probiotic supplementation} did not change the microbiota (both at phylum or phylogenetic levels) on epithelial function leading to a less-disrupted intestinal barrier

\begin{tabular}{|c|c|c|c|c|}
\hline $\begin{array}{l}61 \text { Patients with mild } \\
\text { to moderate } \\
\text { pulmonary disease }\end{array}$ & L. reuteri ${ }^{*}$ ATCC 55730 & $\begin{array}{l}\downarrow \text { Pulmonary } \\
\text { exacerbations and URTI* }\end{array}$ & $\begin{array}{l}\text { Improvement of intestinal } \\
\text { barrier function and } \\
\text { modulation of } \\
\text { immune response }\end{array}$ & Di Nardo et al., 2014 [95] \\
\hline 22 patients aged $2-9$ years & $L G G^{*}$ & $\begin{array}{l}\downarrow \text { Fecal calprotectin } \\
\text { ( } \downarrow \text { intestinal inflammation) }\end{array}$ & $\begin{array}{l}\text { Partial restoration of } \\
\text { healthy intestinal } \\
\text { microbiota that limit } \\
\text { intestinal inflammation }\end{array}$ & Bruzzese et al., 2014 [61] \\
\hline $\begin{array}{l}30 \text { patients in two groups } \\
\text { (probiotic and } \\
\text { placebo group) }\end{array}$ & L. reuteri* & $\begin{array}{l}\downarrow \text { Fecal calprotectin } \\
\text { ( } \downarrow \text { intestinal inflammation) } \\
\text { and } \uparrow \text { digestive comfort }\end{array}$ & $\begin{array}{l}\uparrow \text { Microbial diversity with } \\
\uparrow \text { representation of } \\
\text { Firmicutes. } \downarrow \\
\gamma \text {-Proteobacteria genera } \\
\text { Enterobacteriaceae }\end{array}$ & Del Campo et al., 2014 [56] \\
\hline
\end{tabular}

Jafari et al., 2013 [97] 25 patients aged $7-12$
years (crossover study)

( ${ }^{*}$ LGG = Lactobacillus GG; DCs = dendritic cells; Treg = regulatory T-cells; L. casei = Lactobacillus casei; L. rhamnosus = Lactobacillus rhamnosus; S. thermophilus = Streptococcus thermophiles; B. breve = Bifidobacterium breve; L. acidophilus = Lactobacillus acidophilus; B. infantis = Bifidobacterium infantis; L. bulgaricus = Lactobacillus bulgaricus; TNF- $\alpha=$ tumor necrosis factor alpha; IFN- $\gamma=$ interferon gamma; $L$. reuteri $=$ Lactobacillus reuteri; URTI = upper respiratory tract infections; $B$. animalis = Bifidobacterium animalis; BMI = body mass index; FEV1 = forced expiratory volume $1 ; \downarrow$-decrease; $\uparrow$-increase).

\subsection{Prebiotics in Modulation of Gut Microbiome in CF}

Among available prebiotics, the oligosaccharides present in breast milk are relatively well studied. In healthy infants, breast milk oligosaccharides are associated with increased abundance of Bifidobacterium in an infant's gut, playing a vital role in production of ac- 
etate and prevention of pathogenic infections such as E. coli [100]. Madan et al. noted that breast-milk feeding also was associated with increased diversity of gut microbiota and less respiratory tract colonization in CF infants [20]. Using an in vitro model, Wang et al. demonstrated the interplay between dysbiosis and prebiotics [36]. Here, levels of individual and total SCFA before and after high amylose maize starch fermentation by fecal slurries from CF and healthy participants were estimated [36]. Acetate and total SCFA levels were significantly reduced in CF patients compared to slurries from healthy control participants, while butyrate and propionate levels did not differ [36]. Taxa that showed positive correlations with the production of SCFAs in controls included Dorea, Anaerostipes, Faecalibacterium, and Bacteroides, and were significantly lower in postfermentation CF samples [36]. Acetate concentrations did not have any correlations among CF patient samples. Controls showed butyrate levels positively correlating with a relative abundance of Faecalibacterium, and that propionate was significantly associated with Bacteroides [36]. When CF fecal slurries were used, butyrate levels were strongly correlated with the Clostridium sensu stricto cluster 1 abundance, and propionate concentrations were significantly related to Veillonella fecal levels [36].

\subsection{Effect of Vitamins and Dietary Nutrients on the Modulation of Gut Microbiome in CF}

The effect of vitamins on the modulation of gut microbiota has also been studied, though on smaller scale. Investigators have noted negative and positive associations between intake of antioxidant vitamins with Bacteroides and Firmicutes, respectively [101]. In a randomized study utilizing high-resolution metabolomics, high-dose vitamin D administration demonstrated an anticatabolic effect in adults with CF pulmonary exacerbation [102]. The simultaneous impact in gut microbiota was not evaluated. Long-term enrichment of polyunsaturated fatty acids has been shown to reduce pulmonary involvement and growth reduction in mice studies [103]. Further, mice supplemented with genistein, a soy isoflavone and polyphenol, were associated with reduced microbial diversity compared to a regular diet [104]. The dosage, duration, and long-term impact of administration of these nutrients or nutrient supplements to attain a healthy microbiota remains unknown [49].

\subsection{Effect of Targeted Molecular Therapies on the Modulation of Gut Microbiome in CF}

With the advent of highly effective targeted therapies in $\mathrm{CF}$, evidence of their impact on restoring dysbiosis is emerging. In a small prospective observational study, a six-month course of ivacaftor, a CFTR potentiator, was associated with an increase in Akkermansia (bacterium involved in mucosal protection). Interestingly, the increased abundance of this genus negatively correlated with fecal inflammatory markers [105]. Kopp et al. reported favorable changes in serum metabolites involved in fat and amino-acid pathways after initiating lumacaftor/ivacaftor; however, correlations with the gut microbiome were not studied [106]. The effects of newer modulators such as lumacaftor/ivacaftor and lumacaftor/tezacaftor/ivacaftor on the gut microbiome are still uncertain, but may yield helpful insights into interactions between CF pathology and the microbial milieu.

\section{Conclusions and Future Directions}

With the advancements in science and technology, affordable and significant investigations have contributed substantial progress in understanding the role of the human microbiome in CF. As researchers explore the complex interactions between lung and gut microbial communities in the CF disease process, the focus will need to be directed toward potentially actionable interventions in an effort to manipulate the microbiome in beneficial ways starting early in life. Microbial richness, diversity, and dominant microbiota have the potential to be validated as biomarkers for the disease phenotype, and also can be helpful as prognostic factors [107]. More research is required to understand the dynamic interactions between microbiota and the variety of their subsequent metabolites to possibly identify therapeutic targets for metabolite-based therapy (postbiotics) toward personalized precision medicine [12]. Despite the increasing availability, multiomic technologies are 
still mostly available in research labs and are not utilized in clinical settings. There are numerous limitations of multiomics that need to be considered before routine clinical applications, including the high cost, lack of unique protocols, and challenges in choosing the right sample (e.g., stool microbiota may not be representative of all gut microbes, especially the mucosa-adherent microbiota) $[17,108]$. A large sample size is needed for validation cohorts to overcome false-positive test results $[17,109,110]$.

Metatranscriptomics and metaproteomics offer the advantage of evaluating functional gene expression, but their utilization can be challenging [17]. Stool metatranscriptomics, which reads the transcribed gut mRNAs, are stable only for few minutes and may not entirely represent the in vivo expression $[15,17]$. Also, the transcribed RNA and expressed proteins may lack correlation limiting the interpretation of these modalities [17]. Metaproteomics, which utilizes liquid chromatography or gas chromatography coupled with mass spectrometry (LC/GC-MS), has the drawback of differentiating the origin of a protein (i.e., whether the expressed protein is from the host or is microbial in origin [110].

Similarly, metabolomics (targeted and untargeted), which also utilize LC/GC-MS, has its own limitations. Targeted metabolomics that include a pre-established set of non-protein molecules is preferred to the untargeted method, but not all the microbial molecules are predefined [17]. Untargeted metabolomics is limited by the inability to annotate all the molecules modified by microbial or host metabolism, and also possess the challenge of distinguishing the origin of molecules (host vs. microbial origin) [15,17]. The massive amount of data generated by these sophisticated methods also need advanced analytical computing $[17,109,110]$.

Apart from bacterial microbiota, investigations into other microbial communities such as archaea, viruses (bacteriophages), fungi, and their interactions with the resident bacteriome, as well as the host, is another exciting area in need of more attention $[30,111]$. This is especially important in the context of emerging data that support an altered intestinal virome characteristic in CF patients [112]. Nevertheless, an ever-growing scientific investment in multiomic technology will provide promising opportunities to apply precision medicine strategies by designing more comprehensive and effective $\mathrm{CF}$ therapies in the future.

Author Contributions: Conceptualization, A.T., I.S., and S.S.; writing—original draft preparation, A.T., I.S., and S.S.; writing—-review and editing, A.T., I.S., T.J.S., and S.S. All authors have read and agreed to the published version of the manuscript.

Funding: Senthilkumar Sankararaman is supported by a Developing Innovative Gastroenterology Specialty Training (DIGEST) Program grant from the Cystic Fibrosis Foundation.

Conflicts of Interest: The authors declare no conflict of interest.

\section{References}

1. Cutting, G.R. Modifier Genetics: Cystic Fibrosis. Annu. Rev. Genom. Hum. Genet. 2005, 6, 237-260. [CrossRef] [PubMed]

2. De Lisle, R.C.; Borowitz, D. The Cystic Fibrosis Intestine. Cold Spring Harb. Perspect. Med. 2013, 3, a009753. [CrossRef] [PubMed]

3. Debray, D.; El Mourabit, H.; Merabtene, F.; Brot, L.; Ulveling, D.; Chrétien, Y.; Rainteau, D.; Moszer, I.; Wendum, D.; Sokol, H.; et al. Diet-Induced dysbiosis and genetic background synergize with cystic fibrosis transmembrane conductance regulator deficiency to promote cholangiopathy in mice. Hepatol. Commun. 2018, 2, 1533-1549. [CrossRef]

4. Liessi, N.; Pedemonte, N.; Armirotti, A.; Braccia, C. Proteomics and Metabolomics for Cystic Fibrosis Research. Int. J. Mol. Sci. 2020, 21, 5439. [CrossRef] [PubMed]

5. Lee-Sarwar, K.A.; Lasky-Su, J.; Kelly, R.S.; Litonjua, A.A.; Weiss, S.T. Metabolome-Microbiome Crosstalk and Human Disease. Metabolites 2020, 10, 181. [CrossRef]

6. Zhang, D.; Li, S.; Wang, N.; Tan, H.-Y.; Zhang, Z.; Feng, Y. The Cross-Talk Between Gut Microbiota and Lungs in Common Lung Diseases. Front. Microbiol. 2020, 11, 301. [CrossRef]

7. Albenberg, L.; Kelsen, J. Advances in Gut Microbiome Research and Relevance to Pediatric Diseases. J. Pediatr. 2016, 178, 16-23. [CrossRef]

8. Rinninella, E.; Raoul, P.; Cintoni, M.; Franceschi, F.; Miggiano, G.A.D.; Gasbarrini, A.; Mele, M.C. What is the healthy gut microbiota composition? A changing ecosystem across age, environment, diet, and diseases. Microorganisms 2019, 7, 14. [CrossRef] [PubMed] 
9. Coffey, M.J.; Nielsen, S.; Wemheuer, B.; Kaakoush, N.O.; Garg, M.; Needham, B.; Pickford, R.; Jaffe, A.; Thomas, T.; Ooi, C.Y. Gut Microbiota in Children with Cystic Fibrosis: A Taxonomic and Functional Dysbiosis. Sci. Rep. 2019, 9, 1-14. [CrossRef]

10. Sommer, F.; Bäckhed, F. The gut microbiota-Masters of host development and physiology. Nat. Rev. Microbiol. 2013, 11, 227-238. [CrossRef] [PubMed]

11. Françoise, A.; Héry-Arnaud, G. The Microbiome in Cystic Fibrosis Pulmonary Disease. Genes 2020, 11, 536. [CrossRef] [PubMed]

12. Wong, A.C.; Levy, M. New Approaches to Microbiome-Based Therapies. mSystems 2019, 4, e00122-19. [CrossRef] [PubMed]

13. Budden, K.F.; Gellatly, S.L.; Wood, D.L.A.; Cooper, M.A.; Morrison, M.; Hugenholtz, P.; Hansbro, P.M. Emerging pathogenic links between microbiota and the gut-lung axis. Nat. Rev. Microbiol. 2017, 15, 55-63. [CrossRef]

14. Clemente, J.C.; Manasson, J.; Scher, J.U. The role of the gut microbiome in systemic inflammatory disease. BMJ 2018, 360 , j5145. [CrossRef] [PubMed]

15. Staley, C.; Kaiser, T.; Khoruts, A. Clinician Guide to Microbiome Testing. Dig. Dis. Sci. 2018, 63, 3167-3177. [CrossRef] [PubMed]

16. Sharon, G.; Garg, N.; Debelius, J.; Knight, R.; Dorrestein, P.C.; Mazmanian, S.K. Specialized Metabolites from the Microbiome in Health and Disease. Cell Metab. 2014, 20, 719-730. [CrossRef] [PubMed]

17. Allaband, C.; McDonald, D.; Vázquez-Baeza, Y.; Minich, J.J.; Tripathi, A.; Brenner, D.A.; Loomba, R.; Smarr, L.; Sandborn, W.J.; Schnabl, B.; et al. Microbiome 101: Studying, Analyzing, and Interpreting Gut Microbiome Data for Clinicians. Clin. Gastroenterol. Hepatol. 2019, 17, 218-230. [CrossRef]

18. Nielsen, S.; Needham, B.; Leach, S.T.; Day, A.S.; Jaffe, A.; Thomas, T.; Ooi, C.Y. Disrupted progression of the intestinal microbiota with age in children with cystic fibrosis. Sci. Rep. 2016, 6, 24857. [CrossRef] [PubMed]

19. Loman, B.R.; Shrestha, C.L.; Thompson, R.; Groner, J.A.; Mejias, A.; Ruoff, K.L.; O’Toole, G.A.; Bailey, M.T.; Kopp, B.T. Age and environmental exposures influence the fecal bacteriome of young children with cystic fibrosis. Pediatr. Pulmonol. 2020, 55, 1661-1670. [CrossRef]

20. Madan, J.C.; Koestler, D.C.; Stanton, B.A.; Davidson, L.; Moulton, L.A.; Housman, M.L.; Moore, J.H.; Guill, M.F.; Morrison, H.G.; Sogin, M.L.; et al. Serial analysis of the gut and respiratory microbiome in cystic fibrosis in infancy: Interaction between in-testinal and respiratory tracts and impact of nutritional exposures. MBio 2012, 3, e00251-12. [CrossRef]

21. Yatsunenko, T.; Rey, F.E.; Manary, M.J.; Trehan, I.; Dominguez-Bello, M.G.; Contreras, M.; Magris, M.; Hidalgo, G.; Baldassano, R.N.; Anokhin, A.P.; et al. Human gut microbiome viewed across age and geography. Nature 2012, 486, 222-227. [CrossRef]

22. David, L.A.; Maurice, C.F.; Carmody, R.N.; Gootenberg, D.B.; Button, J.E.; Wolfe, B.E.; Ling, A.V.; Devlin, A.S.; Varma, Y.; Fischbach, M.A.; et al. Diet rapidly and reproducibly alters the human gut microbiome. Nat. Cell Biol. 2014, 505, 559-563. [CrossRef] [PubMed]

23. Carmody, R.N.; Gerber, G.K.; Luevano, J.M.; Gatti, D.M.; Somes, L.; Svenson, K.L.; Turnbaugh, P.J. Diet Dominates Host Genotype in Shaping the Murine Gut Microbiota. Cell Host Microbe 2015, 17, 72-84. [CrossRef] [PubMed]

24. De Filippo, C.; Cavalieri, D.; Di Paola, M.; Ramazzotti, M.; Poullet, J.B.; Massart, S.; Collini, S.; Pieraccini, G.; Lionetti, P. Impact of diet in shaping gut microbiota revealed by a comparative study in children from Europe and rural Africa. Proc. Natl. Acad. Sci. USA 2010, 107, 14691-14696. [CrossRef]

25. Rogers, G.B.; Narkewicz, M.R.; Hoffman, L.R. The CF gastrointestinal microbiome: Structure and clinical impact. Pediatr. Pulmonol. 2016, 51, S35-S44. [CrossRef] [PubMed]

26. Hayden, H.S.; Eng, A.; Pope, C.E.; Brittnacher, M.J.; Vo, A.T.; Weiss, E.J.; Hager, K.R.; Martin, B.D.; Leung, D.H.; Heltshe, S.L.; et al. Fecal dysbiosis in infants with cystic fibrosis is associated with early linear growth failure. Nat. Med. 2020, 26, 215-221. [CrossRef]

27. Wang, B.; Jiang, X.; Cao, M.; Ge, J.; Bao, Q.; Tang, L.; Chen, Y.; Li, L. Altered Fecal Microbiota Correlates with Liver Biochemistry in Nonobese Patients with Non-alcoholic Fatty Liver Disease. Sci. Rep. 2016, 6, 32002. [CrossRef] [PubMed]

28. Louis, P.; Young, P.; Holtrop, G.; Flint, H.J. Diversity of human colonic butyrate-producing bacteria revealed by analysis of the butyryl-CoA: Acetate CoA-transferase gene. Environ. Microbiol. 2010, 12, 304-314. [CrossRef]

29. Venegas, D.P.; de la Fuente, M.K.; Landskron, G.; González, M.J.; Quera, R.; Dijkstra, G.; Harmsen, H.J.M.; Faber, K.N.; Hermoso, M.A. Short chain fatty acids (SCFAs)-mediated gut epithelial and immune regulation and its relevance for inflammatory bowel diseases. Front. Immunol. 2019, 10, 277. [CrossRef]

30. Manor, O.; Levy, R.; Pope, C.E.; Hayden, H.S.; Brittnacher, M.J.; Carr, R.; Radey, M.C.; Hager, K.R.; Heltshe, S.L.; Ramsey, B.W.; et al. Metagenomic evidence for taxonomic dysbiosis and functional imbalance in the gastrointestinal tracts of children with cystic fibrosis. Sci. Rep. 2016, 6, 22493. [CrossRef] [PubMed]

31. Da Silva, H.E.; Teterina, A.; Comelli, E.M.; Taibi, A.; Arendt, B.M.; Fischer, S.E.; Lou, W.; Allard, J.P. Nonalcoholic fatty liver disease is associated with dysbiosis independent of body mass index and insulin resistance. Sci. Rep. 2018, 8, 1-12. [CrossRef] [PubMed]

32. Imrie, J.R.; Fagan, D.G.; Sturgess, J.M. Quantitative evaluation of the development of the exocrine pancreas in cystic fibrosis and control infants. Am. J. Pathol. 1979, 95, 697-707.

33. Meeker, S.M.; Mears, K.S.; Sangwan, N.; Brittnacher, M.J.; Weiss, E.J.; Treuting, P.M.; Tolley, N.; Pope, C.E.; Hager, K.R.; Vo, A.T.; et al. CFTR dysregulation drives active selection of the gut microbiome. PLoS Pathog. 2020, 16, e1008251. [CrossRef]

34. Ooi, C.Y.; Pang, T.; Leach, S.T.; Katz, T.; Day, A.S.; Jaffe, A. Fecal Human $\beta$-Defensin 2 in Children with Cystic Fibrosis: Is There a Diminished Intestinal Innate Immune Response? Dig. Dis. Sci. 2015, 60, 2946-2952. [CrossRef]

35. Gelfond, D.; Ma, C.; Semler, J.; Borowitz, D. Intestinal pH and Gastrointestinal Transit Profiles in Cystic Fibrosis Patients Measured by Wireless Motility Capsule. Dig. Dis. Sci. 2012, 58, 2275-2281. [CrossRef] [PubMed] 
36. Wang, Y.; Leong, L.E.; Keating, R.L.; Kanno, T.; Abell, G.C.; Mobegi, F.M.; Choo, J.M.; Wesselingh, S.L.; Mason, A.J.; Burr, L.D.; et al. Opportunistic bacteria confer the ability to ferment prebiotic starch in the adult cystic fibrosis gut. Gut Microbes 2019, 10,367-381. [CrossRef]

37. Kristensen, M.; Prevaes, S.M.; Kalkman, G.; Tramper-Stranders, G.A.; Hasrat, R.; Groot, K.M.D.W.-D.; Janssens, H.M.; Tiddens, H.A.; Van Westreenen, M.; Sanders, E.A.; et al. Development of the gut microbiota in early life: The impact of cystic fibrosis and antibiotic treatment. J. Cyst. Fibros. 2020, 19, 553-561. [CrossRef]

38. Debyser, G.; Mesuere, B.; Clement, L.; Van De Weygaert, J.; Van Hecke, P.; Duytschaever, G.; Aerts, M.; Dawyndt, P.; De Boeck, K.; Vandamme, P.; et al. Faecal proteomics: A tool to investigate dysbiosis and inflammation in patients with cystic fibrosis. J. Cyst. Fibros. 2016, 15, 242-250. [CrossRef] [PubMed]

39. Vernocchi, P.; del Chierico, F.; Russo, A.; Majo, F.; Rossitto, M.; Valerio, M.; Casadei, L.; la Storia, A.; de Filippis, F.; Rizzo, C.; et al. Gut microbiota signatures in cystic fibrosis: Loss of host CFTR function drives the microbiota entero-phenotype. PLoS ONE 2018, 13, e0208171. [CrossRef]

40. Hoffman, L.R.; Pope, C.E.; Hayden, H.S.; Heltshe, S.; Levy, R.; McNamara, S.; Jacobs, M.A.; Rohmer, L.; Radey, M.; Ramsey, B.W.; et al. Escherichia coli dysbiosis correlates with gastrointestinal dysfunction in children with cystic fibrosis. Clin. Infect. Dis. 2013, 58, 396-399. [CrossRef]

41. Garg, M.; Ooi, C.Y. The Enigmatic Gut in Cystic Fibrosis: Linking Inflammation, Dysbiosis, and the Increased Risk of Malignancy. Curr. Gastroenterol. Rep. 2017, 19, 6. [CrossRef]

42. Héry-Arnaud, G.; Boutin, S.; Cuthbertson, L.; Elborn, S.J.; Tunney, M.M. The lung and gut microbiome: What has to be taken into consideration for cystic fibrosis? J. Cyst. Fibros. 2019, 18, 13-21. [CrossRef]

43. Van Biervliet, S.; Declercq, D.; Somerset, S. Clinical effects of probiotics in cystic fibrosis patients: A systematic review. Clin. Nutr. ESPEN 2017, 18, 37-43. [CrossRef] [PubMed]

44. Schippa, S.; Iebba, V.; Santangelo, F.; Gagliardi, A.; de Biase, R.V.; Stamato, A.; Bertasi, S.; Lucarelli, M.; Conte, M.P.; Quattrucci, S. Cystic fibrosis transmembrane conductance regulator (CFTR) allelic variants relate to shifts in faecal mi-crobiota of cystic fibrosis patients. PLoS ONE 2013, 8, e61176. [CrossRef]

45. Burke, D.; Fouhy, F.; Harrison, M.J.; Rea, M.C.; Cotter, P.D.; O'Sullivan, O.; Stanton, C.; Hill, C.; Shanahan, F.; Plant, B.J.; et al. The altered gut microbiota in adults with cystic fibrosis. BMC Microbiol. 2017, 17, 1-11. [CrossRef]

46. Frost, F.; Kacprowski, T.; Rühlemann, M.; Bülow, R.; Kühn, J.; Franke, A.; Heinsen, F.; Pietzner, M.; Nauck, M.; Völker, U.; et al. Impaired exocrine pancreatic function associates with changes in intestinal microbiota composition and di-versity. Gastroenterology 2019, 156, 1010-1015. [CrossRef] [PubMed]

47. Anitha, M.; Reichardt, F.; Tabatabavakili, S.; Nezami, B.G.; Chassaing, B.; Mwangi, S.; Vijay-Kumar, M.; Gewirtz, A.; Srinivasan, S. Intestinal Dysbiosis Contributes to the Delayed Gastrointestinal Transit in High-Fat Diet Fed Mice. Cell. Mol. Gastroenterol. Hepatol. 2016, 2, 328-339. [CrossRef]

48. Matamouros, S.; Hayden, H.S.; Hager, K.R.; Brittnacher, M.J.; Lachance, K.; Weiss, E.J.; Pope, C.E.; Imhaus, A.-F.; McNally, C.P.; Borenstein, E.; et al. Adaptation of commensal proliferating Escherichia coli to the intestinal tract of young children with cystic fibrosis. Proc. Natl. Acad. Sci. USA 2018, 115, 1605-1610. [CrossRef]

49. Li, L.; Somerset, S. The clinical significance of the gut microbiota in cystic fibrosis and the potential for dietary therapies. Clin. Nutr. 2014, 33, 571-580. [CrossRef]

50. Duytschaever, G.; Huys, G.; Bekaert, M.; Boulanger, L.; De Boeck, K.; Vandamme, P. Dysbiosis of bifidobacteria and Clostridium cluster XIVa in the cystic fibrosis fecal microbiota. J. Cyst. Fibros. 2013, 12, 206-215. [CrossRef]

51. Dayama, G.; Priya, S.; Niccum, D.E.; Khoruts, A.; Blekhman, R. Interactions between the gut microbiome and host gene regulation in cystic fibrosis. Genome Med. 2020, 12, 1-15. [CrossRef]

52. Lee, A.J.; Einarsson, G.G.; Gilpin, D.F.; Tunney, M.M. Multi-Omics Approaches: The Key to Improving Respiratory Health in People with Cystic Fibrosis? Front. Pharmacol. 2020, 11, 1382. [CrossRef]

53. Hoen, A.G.; Li, J.; Moulton, L.A.; O’Toole, G.A.; Housman, M.L.; Koestler, D.C.; Guill, M.F.; Moore, J.H.; Hibberd, P.L.; Morrison, H.G.; et al. Associations between Gut Microbial Colonization in Early Life and Respiratory Outcomes in Cystic Fibrosis. J. Pediatr. 2015, 167, 138-147.e3. [CrossRef] [PubMed]

54. Miragoli, F.; Federici, S.; Ferrari, S.; Minuti, A.; Rebecchi, A.; Bruzzese, E.; Buccigrossi, V.; Guarino, A.; Callegari, M.L. Impact of cystic fibrosis disease on archaea and bacteria composition of gut microbiota. FEMS Microbiol. Ecol. 2016, 93, 230. [CrossRef] [PubMed]

55. Antosca, K.M.; Chernikova, D.A.; Price, C.E.; Ruoff, K.L.; Li, K.; Guill, M.F.; Sontag, N.R.; Morrison, H.G.; Hao, S.; Drumm, M.L.; et al. Altered Stool Microbiota of Infants with Cystic Fibrosis Shows a Reduction in Genera Associated with Immune Programming from Birth. J. Bacteriol. 2019, 201, 00274-19. [CrossRef]

56. Del Campo, R.; Garriga, M.; Pérez-Aragón, A.; Guallarte, P.; Lamas, A.; Máiz, L.; Bayón, C.; Roy, G.; Cantón, R.; Zamora, J.; et al. Improvement of digestive health and reduction in proteobacterial populations in the gut microbiota of cystic fibrosis patients using a Lactobacillus reuteri probiotic preparation: A double blind prospective study. J. Cyst. Fibros. 2014, 13, 716-722. [CrossRef]

57. Duytschaever, G.; Huys, G.; Bekaert, M.; Boulanger, L.; De Boeck, K.; Vandamme, P. Cross-Sectional and Longitudinal Comparisons of the Predominant Fecal Microbiota Compositions of a Group of Pediatric Patients with Cystic Fibrosis and Their Healthy Siblings. Appl. Environ. Microbiol. 2011, 77, 8015-8024. [CrossRef] 
58. Scanlan, P.D.; Buckling, A.; Kong, W.; Wild, Y.; Lynch, S.V.; Harrison, F. Gut dysbiosis in cystic fibrosis. J. Cyst. Fibros. 2012, 11, 454-455. [CrossRef] [PubMed]

59. Enaud, R.; Hooks, K.B.; Barre, A.; Barnetche, T.; Hubert, C.; Massot, M.; Bazin, T.; Clouzeau, H.; Bui, S.; Fayon, M.; et al. Intestinal inflammation in children with cystic fibrosis is associated with Crohn's-like microbiota disturb-ances. J. Clin. Med. $2019,8,645$. [CrossRef]

60. Kaakoush, N.O.; Pickford, R.; Jaffe, A.; Ooi, C.Y. Is there a role for stool metabolomics in cystic fibrosis? Pediatr. Int. 2016, 58, 808-811. [CrossRef] [PubMed]

61. Bruzzese, E.; Callegari, M.L.; Raia, V.; Viscovo, S.; Scotto, R.; Ferrari, S.; Morelli, L.; Buccigrossi, V.; Vecchio, A.L.; Ruberto, E.; et al. Disrupted intestinal microbiota and intestinal inflammation in children with cystic fibrosis and its res-toration with Lactobacillus GG: A randomised clinical trial. PLoS ONE 2014, 9, e87796. [CrossRef] [PubMed]

62. de Freitas, M.B.; Moreira, E.A.M.; Tomio, C.; Moreno, Y.M.F.; Daltoe, F.P.; Barbosa, E.; Neto, N.L.; Buccigrossi, V.; Guarino, A. Altered intestinal microbiota composition, antibiotic therapy and intestinal inflammation in children and adolescents with cystic fibrosis. PLoS ONE 2018, 13, e0198457. [CrossRef] [PubMed]

63. Van Biervliet, S.; Eggermont, E.; Carchon, H.; Veereman, G.; DeBoeck, K. Small intestinal brush border enzymes in cystic fibrosis. Acta Gastro-Enterol. Belg. 1999, 62, 267-271.

64. Van Biervliet, S.; Hauser, B.; Verhulst, S.; Stepman, H.; Delanghe, J.; Warzee, J.; Pot, B.; Vandewiele, T.; Wilschanski, M. Probiotics in cystic fibrosis patients: A double blind crossover placebo controlled study: Pilot study from the ESPGHAN Working Group on Pancreas/CF. Clin. Nutr. ESPEN 2018, 27, 59-65. [CrossRef] [PubMed]

65. Garg, M.; Leach, S.T.; Coffey, M.J.; Katz, T.; Strachan, R.; Pang, T.; Needham, B.; Lui, K.; Ali, F.; Day, A.S.; et al. Age-dependent variation of fecal calprotectin in cystic fibrosis and healthy children. J. Cyst. Fibros. 2017, 16, 631-636. [CrossRef]

66. Garg, M.; Leach, S.T.; Pang, T.; Needham, B.; Coffey, M.J.; Katz, T.; Strachan, R.; Widger, J.; Field, P.; Belessis, Y.; et al. Age-related levels of fecal M2-pyruvate kinase in children with cystic fibrosis and healthy children 0 to 10 years old. J. Cyst. Fibros. 2018, 17, 109-113. [CrossRef]

67. Werlin, S.L.; Benuri-Silbiger, I.; Kerem, E.; Adler, S.N.; Goldin, E.; Zimmerman, J.; Malka, N.; Cohen, L.; Armoni, S.; YatzkanIsraelit, Y.; et al. Evidence of Intestinal Inflammation in Patients with Cystic Fibrosis. J. Pediatr. Gastroenterol. Nutr. 2010, 51, 304-308. [CrossRef] [PubMed]

68. Dhaliwal, J.; Leach, S.; Katz, T.; Nahidi, L.; Pang, T.; Lee, J.; Strachan, R.; Day, A.S.; Jaffe, A.; Ooi, C.Y. Intestinal Inflammation and Impact on Growth in Children with Cystic Fibrosis. J. Pediatr. Gastroenterol. Nutr. 2015, 60, 521-526. [CrossRef]

69. Lee, J.M.; Leach, S.T.; Katz, T.; Day, A.S.; Jaffe, A.; Ooi, C.Y. Update of Faecal Markers of Inflammation in Children with Cystic Fibrosis. Mediat. Inflamm. 2012, 2012, 1-6. [CrossRef]

70. De Lisle, R.C.; Mueller, R.; Boyd, M. Impaired Mucosal Barrier Function in the Small Intestine of the Cystic Fibrosis Mouse. J. Pediatr. Gastroenterol. Nutr. 2011, 53, 371-379. [CrossRef] [PubMed]

71. Hallberg, K.; Grzegorczyk, A.; Larson, G.; Strandvik, B. Intestinal Permeability in Cystic Fibrosis in Relation to Genotype. J. Pediatr. Gastroenterol. Nutr. 1997, 25, 290-295. [CrossRef]

72. Peretti, N.; Marcil, V.; Drouin, E.; Levy, E. Mechanisms of lipid malabsorption in Cystic Fibrosis: The impact of essential fatty acids deficiency. Nutr. Metab. 2005, 2, 11. [CrossRef]

73. De Lisle, R.C. Disrupted tight junctions in the small intestine of cystic fibrosis mice. Cell Tissue Res. 2014, 355, 131-142. [CrossRef] [PubMed]

74. Van Biervliet, S.; Eggermont, E.; Mariën, P.; Hoffman, I.; Veereman, G. Combined impact of mucosal damage and of cystic fibrosis on the small intestinal brush border enzyme activities. Acta Clin. Belg. 2003, 58, 220-224. [CrossRef]

75. Schubert, A.M.; Sinani, H.; Schloss, P.D. Antibiotic-Induced Alterations of the Murine Gut Microbiota and Subsequent Effects on Colonization Resistance against Clostridium difficile. mBio 2015, 6, e00974-15. [CrossRef]

76. Fouhy, F.; Ronan, N.J.; O'Sullivan, O.; McCarthy, Y.; Walsh, A.M.; Murphy, D.M.; Daly, M.; Flanagan, E.T.; Fleming, C.; McCarthy, M.; et al. A pilot study demonstrating the altered gut microbiota functionality in stable adults with Cystic Fibrosis. Sci. Rep. 2017, 7, 6685. [CrossRef] [PubMed]

77. Scott, P.; Anderson, K.; Singhania, M.; Cormier, R. Cystic Fibrosis, CFTR, and Colorectal Cancer. Int. J. Mol. Sci. 2020, 21, 2891. [CrossRef]

78. Yamada, A.; Komaki, Y.; Komaki, F.; Micic, D.; Zullow, S.; Sakuraba, A. Risk of gastrointestinal cancers in patients with cystic fibrosis: A systematic review and meta-analysis. Lancet Oncol. 2018, 19, 758-767. [CrossRef]

79. Hussan, H.; Clinton, S.K.; Roberts, K.; Bailey, M.T. Fusobacterium's link to colorectal neoplasia sequenced: A systematic review and future insights. World J. Gastroenterol. 2017, 23, 8626-8650. [CrossRef]

80. Leung, D.H.; Yimlamai, D. The intestinal microbiome and paediatric liver disease. Lancet Gastroenterol. Hepatol. $2017,2,446-455$. [CrossRef]

81. Wu, H.; Vu, M.; Dhingra, S.; Ackah, R.; Goss, J.A.; Rana, A.; Quintanilla, N.; Patel, K.; Leung, D.H. Obliterative Portal Venopathy Without Cirrhosis Is Prevalent in Pediatric Cystic Fibrosis Liver Disease with Portal Hypertension. Clin. Gastroenterol. Hepatol. 2019, 17, 2134-2136. [CrossRef]

82. Flass, T.; Tong, S.; Frank, D.N.; Wagner, B.D.; Robertson, C.E.; Kotter, C.V.; Sokol, R.J.; Zemanick, E.; Accurso, F.; Hoffenberg, E.J.; et al. Intestinal Lesions Are Associated with Altered Intestinal Microbiome and Are More Frequent in Children and Young Adults with Cystic Fibrosis and Cirrhosis. PLoS ONE 2015, 10, e0116967. [CrossRef] 
83. Fiorotto, R.; Scirpo, R.; Trauner, M.; Fabris, L.; Hoque, R.; Spirli, C.; Strazzabosco, M. Loss of CFTR affects biliary epithelium innate immunity and causes TLR4-NF-кB-mediated inflammatory response in mice. Gastroenterology 2011, 141, 1498-1508.e5. [CrossRef] [PubMed]

84. Rath, T.; Hage, L.; Kügler, M.; Menendez, K.M.; Zachoval, R.; Naehrlich, L.; Schulz, R.; Roderfeld, M.; Roeb, E. Serum Proteome Profiling Identifies Novel and Powerful Markers of Cystic Fibrosis Liver Disease. PLoS ONE 2013, 8, e58955. [CrossRef] [PubMed]

85. Vallianou, N.G.; Stratigou, T.; Tsagarakis, S. Microbiome and diabetes: Where are we now? Diabetes Res. Clin. Pr. 2018, 146, 111-118. [CrossRef] [PubMed]

86. Charlson, E.S.; Bittinger, K.; Haas, A.R.; Fitzgerald, A.S.; Frank, I.; Yadav, A.; Bushman, F.D.; Collman, R.G. Topographical Continuity of Bacterial Populations in the Healthy Human Respiratory Tract. Am. J. Respir. Crit. Care Med. 2011, 184, 957-963. [CrossRef] [PubMed]

87. Boutin, S.; Graeber, S.Y.; Weitnauer, M.; Panitz, J.; Stahl, M.; Clausznitzer, D.; Kaderali, L.; Einarsson, G.; Tunney, M.M.; Elborn, J.S.; et al. Comparison of Microbiomes from Different Niches of Upper and Lower Airways in Children and Adolescents with Cystic Fibrosis. PLoS ONE 2015, 10, e0116029. [CrossRef] [PubMed]

88. Prevaes, S.M.; Piters, W.A.D.S.; Groot, K.M.D.W.-D.; Janssens, H.M.; Tramper-Stranders, G.A.; Chu, M.L.J.; Tiddens, H.A.; Van Westreenen, M.; Van Der Ent, C.K.; Sanders, E.A.; et al. Concordance between upper and lower airway microbiota in infants with cystic fibrosis. Eur. Respir. J. 2017, 49, 1602235. [CrossRef]

89. Madan, J.C. Neonatal Gastrointestinal and Respiratory Microbiome in Cystic Fibrosis: Potential Interactions and Implications for Systemic Health. Clin. Ther. 2016, 38, 740-746. [CrossRef]

90. Marsland, B.J.; Gollwitzer, E.S. Host-microorganism interactions in lung diseases. Nat. Rev. Immunol. 2014, 14, 827-835. [CrossRef]

91. Bazett, M.; Bergeron, M.-E.; Haston, C.K. Streptomycin treatment alters the intestinal microbiome, pulmonary T cell profile and airway hyperresponsiveness in a cystic fibrosis mouse model. Sci. Rep. 2016, 6, srep19189. [CrossRef]

92. Huang, Y.J.; LiPuma, J.J. The Microbiome in Cystic Fibrosis. Clin. Chest Med. 2016, 37, 59-67. [CrossRef]

93. Bilski, J.; Mazur-Bialy, A.; Wojcik, D.; Zahradnik-Bilska, J.; Brzozowski, B.; Magierowski, M.; Mach, T.; Magierowska, K.; Brzozowski, T. The Role of Intestinal Alkaline Phosphatase in Inflammatory Disorders of Gastrointestinal Tract. Mediat. Inflamm. 2017, 2017, 1-9. [CrossRef] [PubMed]

94. Li, L.; Somerset, S. Associations between Flavonoid Intakes and Gut Microbiota in a Group of Adults with Cystic Fibrosis. Nutrients 2018, 10, 1264. [CrossRef]

95. Di Nardo, G.; Oliva, S.; Menichella, A.; Pistelli, R.; De Biase, R.V.; Patriarchi, F.; Cucchiara, S.; Stronati, L. Lactobacillus reuteri ATCC55730 in Cystic Fibrosis. J. Pediatr. Gastroenterol. Nutr. 2014, 58, 81-86. [CrossRef]

96. Bruzzese, E.; Raia, V.; Spagnuolo, M.I.; Volpicelli, M.; De Marco, G.; Maiuri, L.; Guarino, A. Effect of Lactobacillus GG supplementation on pulmonary exacerbations in patients with cystic fibrosis: A pilot study. Clin. Nutr. 2007, 26, 322-328. [CrossRef] [PubMed]

97. Jafari, S.-A.; Mehdizadeh-Hakkak, A.; Kianifar, H.-R.; Hebrani, P.; Ahanchian, H.; Abbasnejad, E. Effects of Probiotics on Quality of Life in Children with Cystic Fibrosis; A Randomized Controlled Trial. Iran. J. Pediatr. 2013, 23, 669-674.

98. Fallahi, G.; Motamed, F.; Yousefi, A.; Shafieyoun, A.; Najafi, M.; Khodadad, A.; Farhmand, F.; Ahmadvand, A.; Rezaei, N. The effect of probiotics on fecal calprotectin in patients with cystic fibrosis. Turk. J. Pediatr. 2014, 55, 475-478.

99. Nikniaz, Z.; Nikniaz, L.; Bilan, N.; Somi, M.H.; Faramarzi, E. Does probiotic supplementation affect pulmonary exacerbation and intestinal inflammation in cystic fibrosis: A systematic review of randomized clinical trials. World J. Pediatr. 2017, 13, 307-313. [CrossRef] [PubMed]

100. Fukuda, S.; Toh, H.; Hase, K.; Oshima, K.; Nakanishi, Y.; Yoshimura, K.; Tobe, T.; Clarke, J.M.; Topping, D.L.; Suzuki, T.; et al. Bifidobacteria can protect from enteropathogenic infection through production of acetate. Nature 2011, 469, 543-547. [CrossRef]

101. Li, L.; Krause, L.; Somerset, S. Associations between micronutrient intakes and gut microbiota in a group of adults with cystic fibrosis. Clin. Nutr. 2017, 36, 1097-1104. [CrossRef] [PubMed]

102. Alvarez, J.A.; Chong, E.Y.; Walker, D.I.; Chandler, J.D.; Michalski, E.S.; Grossmann, R.E.; Uppal, K.; Li, S.; Frediani, J.K.; Tirouvanziam, R.; et al. Plasma metabolomics in adults with cystic fibrosis during a pulmonary exacerbation: A pilot randomized study of high-dose vitamin D3 administration. Metabolism 2017, 70, 31-41. [CrossRef]

103. Portal, C.; Gouyer, V.; Léonard, R.; Husson, M.-O.; Gottrand, F.; Desseyn, J.-L. Long-term dietary (n-3) polyunsaturated fatty acids show benefits to the lungs of Cftr F508del mice. PLoS ONE 2018, 13, e0197808. [CrossRef]

104. Argo, K.B. Gut Microbiome Diversity and Community Structure Following Dietary Genistein Treatment in a Murine Model of Cystic Fibrosis. Master's Thesis, Arizona State University, Tempe, AZ, USA, 2019.

105. Ooi, C.Y.; Syed, S.A.; Rossi, L.; Garg, M.; Needham, B.; Avolio, J.; Young, K.; Surette, M.G.; Gonska, T. Impact of CFTR modulation with Ivacaftor on Gut Microbiota and Intestinal Inflammation. Sci. Rep. 2018, 8, 1-8. [CrossRef] [PubMed]

106. Kopp, B.T.; McCulloch, S.; Shrestha, C.L.; Zhang, S.; Sarzynski, L.; Woodley, F.W.; Hayes, D. Metabolomic responses to lumacaftor/ivacaftor in cystic fibrosis. Pediatr. Pulmonol. 2018, 53, 583-591. [CrossRef]

107. Kashyap, P.C.; Chia, N.; Nelson, H.; Segal, E.; Elinav, E. Microbiome at the frontier of personalized medicine. In Mayo Clinic Proceedings; Elsevier: Amsterdam, The Netherlands, 2017.

108. Rezasoltani, S.; Bashirzadeh, D.A.; Mojarad, E.N.; Aghdaei, H.A.; Norouzinia, M.; Shahrokh, S. Signature of gut microbiome by conventional and advanced analysis techniques: Advantages and dis-advantages. Middle East J. Dig. Dis. 2020, 12, 5. [CrossRef] 
109. Virkud, Y.V.; Kelly, R.S.; Wood, C.; Lasky-Su, J.A. The nuts and bolts of omics for the clinical allergist. Ann. Allergy Asthma Immunol. 2019, 123, 558-563. [CrossRef]

110. Galloway-Peña, J.; Hanson, B. Tools for Analysis of the Microbiome. Dig. Dis. Sci. 2020, 65, 674-685. [CrossRef] [PubMed]

111. Güemes, A.G.C.; Lim, Y.W.; Quinn, R.A.; Conrad, D.J.; Benler, S.; Maughan, H.; Edwards, R.; Brettin, T.; Cantú, V.A.; Cuevas, D.; et al. Cystic Fibrosis Rapid Response: Translating Multi-omics Data into Clinically Relevant Information. mBio 2019, 10, e00431-19. [CrossRef]

112. Coffey, M.J.; Low, I.; Stelzer-Braid, S.; Wemheuer, B.; Garg, M.; Thomas, T.; Jaffe, A.; Rawlinson, W.D.; Ooi, C.Y. The intestinal virome in children with cystic fibrosis differs from healthy controls. PLoS ONE 2020, 15, e0233557. [CrossRef] [PubMed] 